\title{
Asymmetrical Rolling of Aluminum Alloys and Steels: A Review
}

\author{
Gabriela Vincze ${ }^{1, *(\mathbb{D}}$, Fábio J.P. Simões ${ }^{2} \mathbb{D}$ and Marilena C. Butuc ${ }^{1}$ \\ 1 TEMA-Centre of Mechanical Technology and Automation, Department of Mechanical Engineering, \\ University of Aveiro, 3810-193 Aveiro, Portugal; cbutuc@ua.pt \\ 2 Centre for Rapid and Sustainable Product Development, Polytechnic of Leiria, \\ 2430-028 Marinha Grande, Portugal; fabio.simoes@ipleiria.pt \\ * Correspondence: gvincze@ua.pt
}

Received: 30 June 2020; Accepted: 17 August 2020; Published: 21 August 2020

check for updates

\begin{abstract}
Asymmetric rolling is an attractive metal forming process due to its simplicity, low cost and capability to produce unique characteristics in materials. The asymmetry promoted by the process leads to a formation of a large collection of texture components and a refined structure which is capable to improve the mechanical behavior of metallic materials. The aim of this work is to present a perspective of the process and to construct the bases for future development and application of this technique. Thus, several aspects are addressed such as process methods (i.e., dissimilarity of the rolls diameters, rolls angular speed or friction conditions), the process parameters (i.e., total thickness reduction, thickness reduction per pass, peripheral speed ratio, rolling routes) and their effect on material properties, including texture and microstructure evolution, and mechanical properties. This review is focused on the experimental description of asymmetric rolling applied to aluminum alloys and steels. Although the asymmetric rolling application was mostly at a laboratory scale, there is a good perspective for its implementation in the industry. The pros and cons based on the up to date literature and authors' experience are presented and discussed.
\end{abstract}

Keywords: asymmetric rolling; texture; microstructure; mechanical behavior; aluminum alloys; steels

\section{Introduction}

Nowadays, the demanding request for lighter and safer structures, the low cost, recyclability, and green manufacturing is a priority. Sheet metal manufacturing is an excellent option to satisfy all the mentioned targets. Moreover, the rolling process is indispensable to produce sheet metals. Thus, a new form of rolling appeared to improve the material properties during the rolling process. Asymmetric rolling (acronym ASR) is a process that can lead to grain refinement and/or shear texture components which are associated with an increase in strength and formability. The first study in asymmetric rolling has been performed in 1948 by Sachs and Klinger [1] for the development of a homogeneous deformation model. Based on this first approach, some researchers used this concept to study the evolution of rolling process parameters, such as rolling torque, force separation or sheet curvature [2-7]. Others studied the metal flow behavior during asymmetric rolling [8,9] and the relation between geometrical parameters and the initial blank and the kinetics of material [10-13]. However, it can be observed that not much attention was paid to this process in the past, compared with the increased number of publications during the current century. Industrially, asymmetric rolling is also studied in the context of thin sheet rolling as a means to attain improvements in strip profile and reduce rolling force, especially when combined with other modifications such as work rolls cross angles and work rolls shifting $[14,15]$. From a perspective of material properties, many studies regarding the process parameters and their impact on crystallographic texture evolution and grain refinement based 
on experimental and numerical approaches were reported after 2000. However, fewer results have been presented regarding the mechanical behavior of the rolled material. The asymmetric rolling has been applied over these years for diverse materials, such as steel, aluminum, copper, magnesium and titanium. Within these, it is worth to mention that the most studied and important were aluminum alloys and steels, which are the materials selected for this review. The advantages of using these materials reside on the fact that they offer a very good combination of mechanical properties, cost and recyclability. Two major research lines have been trailed in the past, namely: (i) introducing a large amount of strain to produce severe plastic deformation and consequently grain refinement [16-22]; and (ii) introducing a small amount of strain using only one rolling pass and keeping the focus on the change of texture components [21,23]. The purpose of this paper is to analyze and summarize the most relevant information regarding the asymmetric rolling process of aluminum alloys and steels, from an experimental point of view. The present work is organized in five sections, starting with the process methodology, followed by texture evolution, microstructure evolution, mechanical behavior and ending with the conclusions and future perspectives on this technology.

\section{Methodology of Asymmetric Rolling}

The fundament of asymmetric rolling is to produce a differential speed between the upper and bottom surface of the rolled sheet that promotes shear deformation through its thickness. This can be achieved by three methods:

1. Different diameters of the rolls (Figure 1a)

2. Different rotation speed of the rolls (Figure $1 b$ )

3. Different friction coefficients between the surface of the material and each one of the rolls (Figure 1c)

Schematic representation of the three methods is presented in Figure $1 \mathrm{a}-\mathrm{c}$, including the values of process parameters existing for each case in particular.

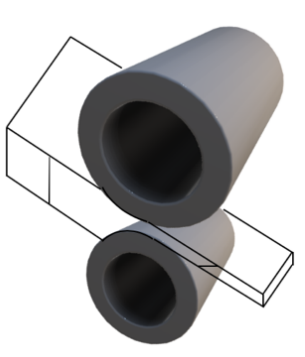

(a)

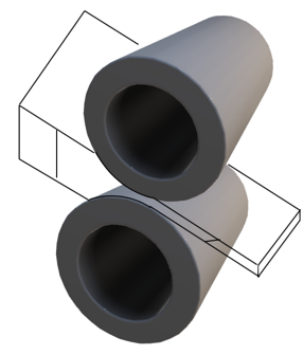

(b)

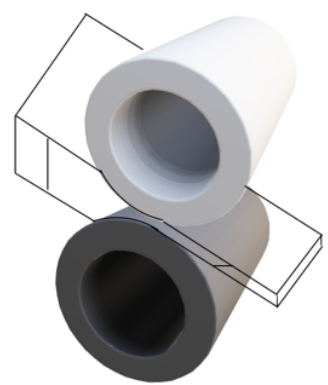

(c)
Diameters of the rolls Angular velocities Friction coefficients Material surfaces speeds

$$
\begin{aligned}
& d_{\text {up }} \neq d_{\text {down }} \\
& \omega_{\text {up }}=\omega_{\text {down }} \\
& \mu_{\text {up }}=\mu_{\text {down }} \\
& V_{\text {up }} \neq V_{\text {down }}
\end{aligned}
$$

$$
\begin{gathered}
d_{\text {up }}=d_{\text {down }} \\
\omega_{\text {up }} \neq \omega_{\text {down }} \\
\mu_{\text {up }}=\mu_{\text {down }} \\
V_{\text {up }} \neq V_{\text {down }}
\end{gathered}
$$

$$
\begin{aligned}
d_{\text {up }} & =d_{\text {down }} \\
\omega_{\text {up }} & =\omega_{\text {down }} \\
\mu_{\text {up }} & \neq \mu_{\text {down }} \\
V_{\text {up }} & \neq V_{\text {down }}
\end{aligned}
$$

Figure 1. Asymmetric rolling process methods and parameters.

As it can be observed from Figure 1, all three methods lead to a differential speed of the material surfaces that is accompanied by the movement of the two neutral points (i.e., the point where the sheet surfaces speed is equal to the circumferential speed of the rolls) of both rolls, which in case of conventional rolling ( $\mathrm{CR}$, or symmetric rolling, i.e., without any asymmetry of the process) are aligned vertically. The line connection between the two neutral points shows clearly that a shear deformation through the thickness is imposed on the material. Schematic representation of this fact is shown in Figure 2. Sometimes, two or all three methods are combined. For example, 
a single-roll drive asymmetric rolling is used for production of ultra-thin strips mostly for applications in micromanufacturing, where in addition to the speed ratio, the diameters of the rolls are different [24].

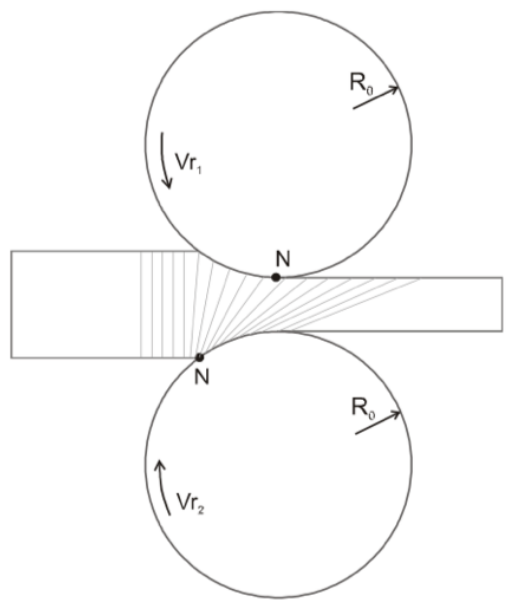

(a)

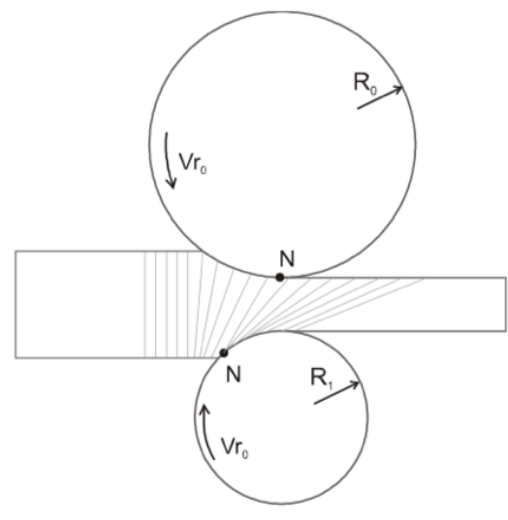

(b)

Figure 2. Representation of the new positions of the neutral points $(\mathrm{N})$ for the two surfaces of the sheet during asymmetric rolling: (a) for the case of identical roll diameters and (b) for the case of different roll diameters (adapted from [25], with permissions from authors, 2020).

Several studies have been devoted to analyses of the rolling process parameters of ASR process such as torque and pressure of the mill, curvature and shape of the rolled sheet, by analytic models [11,26-31] or finite element modeling (FEM) [6,32-34]. A study by Grydin et al. [35] on a two-phase low carbon steel reported a reduction of rolling force to half compared to CR. Moreover, they reported for the same gap between the rolls a higher reduction per pass (RPP) in case of ASR compared to CR. This was also observed by us, for all the materials tested in ASR and CR in our laboratory. As a general remark, the ASR process reduces the torque and the pressure of the rolls considerably, and this reduction increases with the increase of the distance between the two neutral points. In other words, increasing the asymmetry of the process leads to higher shear deformation and a reduction of the torque. The final shear strain along the thickness is strongly dependent on the position of neutral points [36]. Ideally, the asymmetry imposed needs to be determined in a way in which the neutral points exist in the deformation zone, since increasing the asymmetry beyond a critical level does not increase the shear strains imposed through the thickness. The shape of the sheet is dependent on the process parameters, the material thickness and the material type. An important issue in ASR is the bending of the sheet due to the asymmetry imposed. Usually, the sheet follows the roll with higher circumferential speed leading to a concave curvature as represented in Figure 3. According to Wroński et al. [23] the bending can be useful in the last step of rolling, preparing the sheet for the coiling operation. A recent study of Li et al. [37] on ASR of a thick plate of commercial-purity aluminum shows that the bending direction depends on the thickness reduction. It is on the side in contact with the lower speed roll for low reduction and on the opposite side for high reduction. It is a common agreement that the bending increases with increasing the asymmetry of the process and can be reduced and controlled by changing the asymmetry. To do it, the FEM analyses are recommended for a faster solution $[23,38]$. 


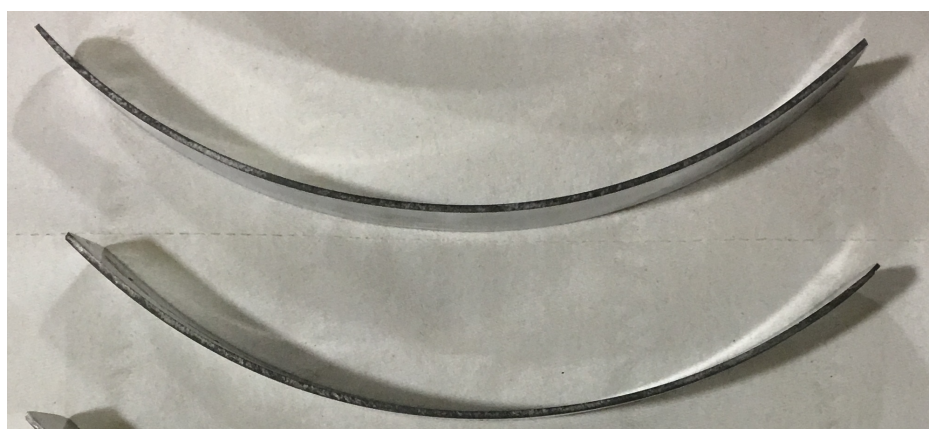

Figure 3. Sample bent after asymmetric rolling.

\subsection{Circumferential Speed Ratio}

The asymmetric rolling with a difference in the circumferential speed ratio $V=\omega R$ includes the two cases mentioned before which are related to the two variables $\omega$ (angular velocity) and $R$ (radius of the rolls). Both methods are described as the ratio (upper roll/lower roll) of one of these two variables while the other is kept equal, namely: (i) different angular speeds and same diameters; (ii) same angular speeds and different diameters. It was demonstrated that for aluminum alloys and steels the optimum roll radius is around 1.5 leading to a uniform shear deformation through the thickness $[39,40]$ and also to a considerable reduction of the normal pressure [41]. However, it is worth to mention that the asymmetry imposed by the roll speed ratio seems to be more versatile compared to the roll radius ratio since changing the speeds is easier than replacing the rolls.

\subsection{Dissimilarity of Friction Conditions}

Imposing asymmetric rolling by different friction conditions between the upper and lower roll is possible but more difficult to control. Moreover, most of the time this is coupled with the circumferential speed ratio since the ASR process occurs usually without lubrication, leading to a near sticking friction and sometimes even to have the material sticking to the roll's surface. Lee and Lee [18] concluded that for pure aluminum the friction condition in ASR corresponds to a friction coefficient $(\mu)$ between 0.3 and 0.5. The same variation was established for other aluminum alloys and steels [42]. Jin and Lloyd [43] carefully investigated the importance of friction conditions in ASR. They performed tests in: (i) low frictional conditions by using Norpar $15+9 \%$ Epal $1416+2 \%$ methyl laureate solution as a lubricant; (ii) medium frictional conditions by using Norpar 15 as a lubricant and (iii) high frictional conditions by dry rolling and cleaning the rolls with hexane. They concluded that the formation of ideal shear texture components is impossible in the absence of high friction conditions and in case of high friction conditions the formation of these texture components is limited to $1 / 4$ of sheet thickness. In conclusion, high friction conditions are mandatory for ASR rolling, but careful attention is necessary for maintaining the same friction conditions during the process (i.e., avoiding the material sticking on the surface of the rolls).

\subsection{Rolling Routes}

It is well known that material response depends on its strain path history. Many researchers analyzed and currently investigate the material response to complex loading paths which occur frequently during industrial sheet metal forming processes. In the asymmetric rolling process, the strain path changes are used to produce a desired property in the rolled material. Thus, four strain paths can be attained by a simple rotation of the sheet as illustrated in Figure 4 and explained in what follows:

Case 1: no rotation between 2 subsequent passes occurs; in this case the shear deformation increases with the increase of the number of passes; the Up and Down surfaces of the sheet are kept. 
Case 2: $\quad 180^{\circ}$ rotation relative to transverse direction (TD) between 2 subsequent passes; in this case the shear deformation increases with the increase of the number of passes; the Up and Down surfaces are switched.

Case 3: $180^{\circ}$ rotation relative to rolling direction (RD) between 2 subsequent passes; the shear deformation is reversed; the increase of number of passes is equivalent to cyclic shear; the Up and Down surfaces are switched.

Case 4: $\quad 180^{\circ}$ rotation relative to normal direction (ND) between 2 subsequent passes; the shear deformation is reversed; the increase of number of passes is equivalent to cyclic shear; the Up and Down surfaces of the sheet are kept.

How the material is processed has a big influence on its properties. For example, in cases 3 and 4 reverse shear is promoted, and this is essential for the formation of ideal shear components of texture. This observation was reported for steels [39] and aluminum alloys [40]. The importance of texture components is explained in detail in the next section.

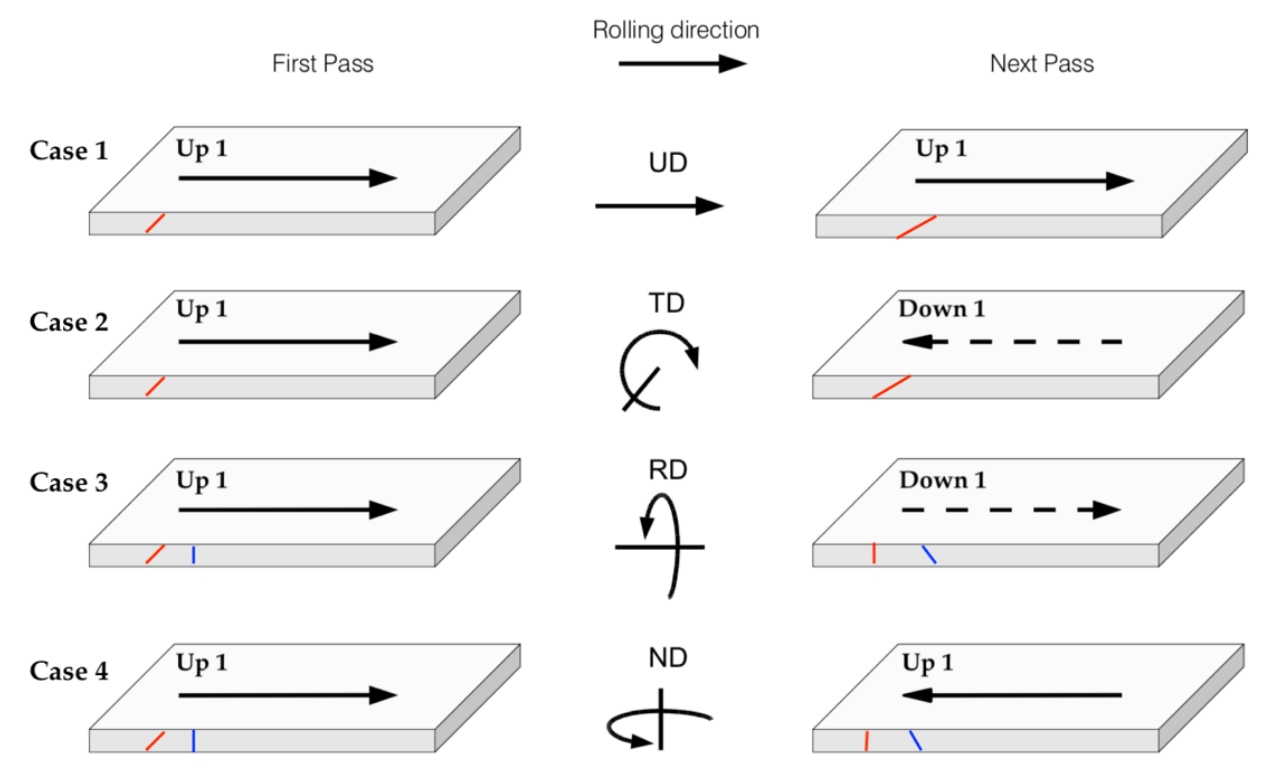

Figure 4. Asymmetric rolling routes (adapted from [25], with permissions from authors, 2020). Up1 and Down1 are the surfaces of the plate/sheet.

\section{Texture}

The texture is the preferred distribution of the crystallographic orientations of grains within a polycrystalline material. This orientation is relative to a macroscopic reference system (the sample reference system), and, is usually described by the $\{\mathrm{hkl}\}<\mathrm{uvw}>$ notation. In sheet metal forming, this means the $\{\mathrm{hkl}\}$ crystallographic plane is parallel to the sample Normal Direction (ND) and the crystallographic direction $<\mathrm{uvw}>$ is parallel to the sample Rolling Direction (RD). Plastic deformation can occur by slip on specific planes and in specific directions within the crystal (the slip system), causing the movement of dislocations in the crystal. Plastic deformation can also occur by twinning, where a movement of atomic planes originates in symmetrically oriented regions without slip. Deformation by slip is the most common mechanism for $b c c$ and $f c c$ metals, whereas twinning is the most prevalent in $h c p$ metals but also in some $b c c$ metals such as tungsten and $b c c$ iron or in $f c c$ metals such as twinning-induced plasticity (TWIP) steels. A combination of both mechanisms is also possible. In a polycrystalline material, each grain is constrained by its neighbors. Hence, the deformation of a crystal depends not only on its orientation but also on the orientation of the grains surrounding it. Thus, the material deformation response is strongly dependent on its crystallographic texture. 
The textures of materials are linked to their structure $(f c c, b c c, h c p)$ and to the processing route and annealing state. Most metals are processed using plastic deformation, which means their crystallographic textures will be the result of the interaction between their structures and the specific stress states originated during these routes. It is possible to identify a set of typical textures generated during plastic deformation. Others are observed when specimens undergo recrystallization. Those are usually generated at the expense of deformation texture components. Other texture components have been associated with specific deformation modes, such as shear. The main texture components are summarized in Table 1 and a selection is represented in Euler space in Figure 5.

Table 1. Main texture components orientation in Euler space.

\begin{tabular}{lllccc}
\hline \multirow{2}{*}{ Type } & Component & $\{$ hkl $\}<$ uvw $>$ & \multicolumn{3}{c}{ Euler Angles (Bunge) } \\
\cline { 3 - 5 } & & & $\mathbf{\boldsymbol { \phi } _ { \mathbf { 1 } }}$ & $\mathbf{\Phi}$ & $\boldsymbol{\phi}_{\mathbf{2}}$ \\
\hline \multirow{3}{*}{ Deformation } & Brass & $\{011\}<211>$ & 35 & 45 & 0 \\
& S & $\{123\}<634>$ & 55 & 35 & 65 \\
& Copper & $\{112\}<111>$ & 90 & 30 & 45 \\
& Dillamore & $\{4411\}<11118>$ & 90 & 27 & 45 \\
\hline \multirow{5}{*}{ Shear } & Rotated Cube (RC) & $\{001\}<110>$ & 0 & 0 & 45 \\
& E & $\{111\}<110>$ & 0 & 55 & 45 \\
& F & $\{111\}<112>$ & 90 & 55 & 45 \\
& I & $\{112\}<110>$ & 0 & 35 & 45 \\
\hline \multirow{5}{*}{ Recrystallization } & Goss & $\{011\}<001>$ & 0 & 45 & 0 \\
& Cube & $\{001\}<100>$ & 0 & 0 & 0 \\
& Rotated Cube RD1 & $\{013\}<100>$ & 0 & 20 & 0 \\
& Rotated Cube RD2 & $\{023\}<100>$ & 0 & 35 & 0 \\
& Rotated Cube ND1 & $\{001\}<310>$ & 20 & 0 & 0 \\
& P & $\{001\}<320>$ & 35 & 0 & 0 \\
& Q & $\{011\}<122>$ & 70 & 45 & 0 \\
& R & $\{013\}<231>$ & 55 & 20 & 0 \\
& & $\{124\}<211>$ & 55 & 75 & 25 \\
\hline
\end{tabular}

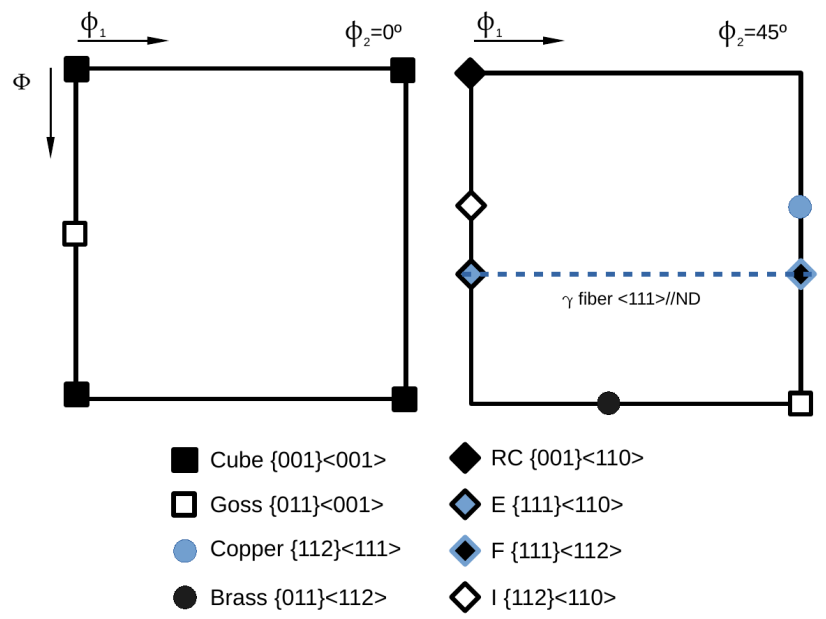

Figure 5. Texture components (selection) representation in Euler space.

Mechanical response of metals is controlled by texture, grain morphology and size and alloying elements. Concerning texture, the typical processing route of casting followed by rolling and thermal treatment has been studied extensively to find out how the desired texture components can be generated. This is especially important in the case of sheets. Each texture component has been correlated with the mechanical response of the material. Optimal combinations of texture components have been sought after, to achieve the desired mechanical response. 
In sheets, one of the most significant indicators of this response is anisotropy. It is characterized by the $r$ value, the ratio of the true plastic strains in width and thickness directions in uniaxial tensile test. Higher values of $r$ are desirable because this means the sheet can accommodate higher deformations before failing by excessive thinning (necking). Thus, higher $r$ means increased formability. Usually, $r$ values are determined for the RD, the TD, and a $45^{\circ}$ to RD direction. The mean $r$ value, $r_{m}=\left(r_{0}+2 r_{45}+r_{90}\right) / 4$ and the planar anisotropy value, $\Delta r=\left(r_{0}-2 r_{45}+r_{90}\right) / 2$ are calculated as indicators of formability. Higher $r_{m}$ indicates overall increased resistance to necking, and higher $\Delta r$ value means increased anisotropy and hence a higher potential for localized necking and asymmetry in plastic deformation.

Investigations of the manipulation of texture towards increased formability led to the determination of the effect of each relevant texture component on the resulting $r_{m}$ and $\Delta r$ values. For example, it is known that recrystallization components, especially Cube, cause low values of $r_{45}$ whereas Copper, Brass and $S$ components (the so-called $\beta$ fiber) cause $r_{45}$ to increase. Textures where the $<111>$ plane normal is parallel(//) to ND, or $<111>/ / \mathrm{ND}$ also called $\gamma$ fiber texture components, (see Table 1 and Figure 5) were predicted to originate higher $r_{m}$ values, Reference [44] which is consistent with the observation of higher formability displayed by materials that present these textures upon processing, such as low carbon steels [45].

Such textures are not readily obtainable using the conventional processing route for $f c c$ metals such as aluminum (rolling followed by annealing). However, they are observed to appear at the surface of rolled sheets, as the result of intense shear strains that are imposed during the process. Because of this, processes imposing an increased shear deformation have been tested with the aim of producing $<111>$ / / ND texture components [46]. Asymmetric rolling is one of those processes.

\subsection{Texture of Aluminium Alloys}

ASR was first studied as a means to attain the $<111>/ /$ ND texture components, which are deemed to enhance the mechanical response of sheets, especially formability. Earlier studies [40,47-49] investigated the processing parameters to attain such texture components in pure aluminium, 3XXX and 5XXX alloys. High friction conditions, as well as high thickness reduction per rolling pass, were identified as essential for obtaining those texture results.

Reversing the rolling direction between each rolling pass, namely around ND, RD and TD (as shown on Figure 4), was also studied by FEM, and predicted to be indispensable for the formation of ideal shear textures [18,40]. However, Jin and Lloyd [50] implemented rolling reversal (not clarified around which axis) on AA5754 and observed this method to be ineffective for that purpose, while still increasing texture randomization upon annealing. Other studies with TD rolling reversal [51], or no rolling reversal [52,53] observed the ASR rolled specimens to display some ideal shear texture components, but a larger part appears to be as the rotated cube component $(\{001\}<110>, R C$, see Table 1$)$, which does not yield significantly higher $r$ values. Zanchetta et al. [54] used high friction conditions on the rolling routes to increase the asymmetry ratio. They obtained an extra rotation of the RC component around ND on the surface of the sheet. Cho et al. [55] showed that a speed ratio of 2 promoted a strong shear texture of rotate cube through the entire sheet thickness.

A reversal of shear strains occurs on the surface of the sheet also in conventional rolling. This is because before neutral point the roll circumferential speed is higher than the speed of the sheet and after the neutral point the opposite takes place. This difference in speeds of the sheet and rolls causes shear strains in opposite directions at the entrance and exit of the rolls. In ASR, the neutral point position is not symmetric-see Figure 2. Thus, although there is always a degree of shear strain reversal, its amount depends on the process parameters, namely speed ratio, thickness reduction per pass and friction. Lee and Lee [18] investigated a rolling schedule where the last rolling pass was reversed around $\mathrm{RD}$, with a lower thickness reduction imposed, compared to the previous rolling passes. The desired $<111>/ /$ ND texture components were obtained. Nam et al. [56] studied a rolling route that led to a significant increase in calculated $r$ value. First, they rolled the AA1050 sheet using 
ASR with $84 \%$ reduction in thickness, followed by annealing at $500{ }^{\circ} \mathrm{C}$ for $1 \mathrm{~h}$, followed by a new ASR schedule with $10 \%$ and $20 \%$ reduction in thickness. Finally, the sheet was annealed once again. The procedure originated both $<111>/ / N D$ and $\{001\}<110>(\mathrm{RC})$ components. While the first is favorable for $r$ value, the latter is not. The sheet was then annealed and rolled again using ASR with a low reduction in thickness. Upon the second annealing, the $\{001\}<110>$ texture component was reduced, causing predicted $r$ values to reach 1.3 which was 2.13 times higher than the $r$ of the initial material. The wide range of ASR methods employed among the studies mentioned may explain the differences observed. It seems reasonable to conclude that shear texture components can be obtained from deformation textures by adequate rotation of those textures around TD and have fundamental contribution for the change of the material properties. This texture rotation can be achieved effectively by controlling the rolling strain, combined with proper (RD or ND) rolling reversal of the sheet between each pass.

Another of the frequent issues reported is the fact that the shear texture components are difficult to produce throughout the sheet thickness [57]. In fact, a significant part of the studies mentions methods for promoting proper conditions for this purpose, e.g., [43]. Shore et al. [58] indicate, using FEM simulations, the set of conditions that would result in texture homogenization during ASR, confirming that increasing difference in roll radii (or velocity ratio), increasing friction and increasing reduction per pass contribute to "decrease texture heterogeneity and increase the penetration of shear strain through the sheet thickness". Even when the mentioned texture components are not attained, using ASR can lead to texture softening (increase in fraction of random orientations), and to a decrease in measured $\Delta r$ values [59].

The effects of heat treatments are also studied in this context. Upon recrystallization annealing, ASR specimes textures are observed to evolve partially towards randomization $[49,50,60]$, while any existing $<111>/ / N D$ shear components tend to remain stable. This is a different behavior from the one observed in conventionally rolled specimens, in which deformation texture components evolve to a strong cube texture upon recrystallization. The stability of shear texture components upon recrystallization annealing was considered as one of the explanations for improved experimental $r$ values observed [48]. For 6XXX alloys, studies involving asymmetric warm rolling can be found [61,62]. A significant change in texture after annealing, especially an absence of the Cube components, is observed. This is one of the factors contributing to the significant increase in $r$ values. It seems that the rolling temperature did not influence the post-rolling heat treatment, since other studies of ASR at room temperature reach similar conclusions [21,63]. The relative stability of shear texture components may be explained by a continuous recrystallization mechanism, enhanced by the decreased of dislocations density as a results of dislocations interaction in the deformed grains, promoting grain growth while keeping the same orientation [18].

A different technique - twin-roll casting and subsequent symmetric and asymmetric rolling-was implemented by several authors [55,63-66]. These studies showed that the initial sheet texture components (after twin-roll casting) were different than those of the conventional processing route (Direct Casting followed by hot-rolling). $<110>/ / \mathrm{ND}$ texture was formed by this route and was observed to be transformed into $<111>/ / \mathrm{ND}$ texture upon the application of shear deformation from ASR. Texture evolution upon annealing resulted in a combination of components not found in CR. Ren et al. [63] observed that, for a 6016 alloy, the shear texture of the annealed ASR sheet was enhanced during recrystallization, at the expense of Cube texture, resulting in an increase of the $r$ value. In a subsequent work, Ren et al. [66] also observed and explained the transformation of an initial Cube texture into a combination of deformation textures components and shear textures components after ASR, while upon annealing those shear texture components became reinforced and prevailed over Cube components. This was explained by the relative spatial orientation of those texture components, facilitating the transition from deformation texture components to shear texture components. Cheon et al. [64] observed that ASR generated randomization of texture, which caused planar anisotropy values close to zero while maintaining strength and ductility. 


\subsection{Texture of Steels}

Studies involving asymmetric rolling of low carbon steels are frequent. The improvement of texture is sought for optimization of mechanical properties, especially $r$ values, but also tensile strength and ductility. The processing of steels is initially done via hot-rolling. If this operation is performed above the austenitization temperature, where iron exists as an $f_{c c} \gamma$ phase (austenite), a recrystallization texture is obtained. Otherwise, austenite will retain a deformation texture after rolling. In any case, there is an evolution of that initial texture with subsequent phase transformation. The texture of austenite changes when iron transforms to the $b c c \alpha$ phase upon cooling. In the case of the recrystallized austenite, the starting texture is Cube. Upon cooling it transforms into $R C\{001\}<110>$ and also $\{113\}<110>$. These components are associated with low $r_{m}$ values. But if the starting austenite has a deformed texture, meaning the $\{110\}<112>$ component is prevalent, then this component transforms upon cooling to the $\{332\}<112>$, in the $b c c$ structure. Upon cold rolling of this material, that texture transforms eventually into $\{111\}<112>$ and $\{111\}<110>$, which are part of the $\gamma$ fiber and are associated with high $r_{m}$ values [45]. Hence there is a fundamental difference between steels and aluminum alloys: in the latter, if the initial texture is cube $\{001\}<100>$, it cannot be transformed efficiently to any shear texture except $\{001\}<110>$, associated with low $r_{m}$ and high $\Delta r$ value. Steels can be processed to obtain those shear texture components by taking advantage of texture evolution by both phase change and deformation procedure. Thus, $\gamma$ fiber is more readily attainable in steels.

ASR in steel can be performed with roll speed ratios within the range of 1.04 [67] to 2.0 [68]. The reduction per pass is typically within the range $12.5 \%$ [69]-30\% [68], which is lower than those used for aluminum alloys. Total reductions are also somewhat lower but can reach $80 \%$ (e.g., [68]).

Lee and Lee [39] studied texture development during asymmetric rolling using FEM with full constraints Taylor model. An experimental procedure-rolling of an interstitial-free (IF) steel at $700{ }^{\circ} \mathrm{C}$, thus having $b c c$ structure-was carried out for validation. The total reduction was $70 \%$, while the reduction per pass was $20 \%$. Results indicate that the ideal shear deformation texture, as in the case of aluminum alloys, is not generated by unidirectional asymmetric rolling but rather by reversing the rolling direction as shown in cases 3 and 4 of Figure 4. This is confirmed by Tóth et al. [69], by means of polycrystal simulations using the Visco-Plastic Self-Consistent (VPSC) model. In their work, asymmetrical rolling was simulated by imposing cyclic rotation around RD between the passes. This led to higher $r_{m}$ values than conventional rolling. In the same work [69], the experimental $r$ values were measured and confirmed this main finding - average $r_{m}=1.08$ and $\Delta r=0.07$ for ASR specimens and $r_{m}=0.99$ and $\Delta r=0.13$ for CR specimens. As in the Lee and Lee study [39], the thickness reduction per pass was not high-12.5\% to $26.5 \%$ - and its influence was not addressed by these authors either.

Lapovok et al. [70] also performed ASR on an IF steel with a rotation around the RD direction between passes. Texture modification led to a decrease of the in-plane anisotropy. This was stated to be one of the main effects of asymmetric rolling. The thickness reduction per pass was not explicitly indicated, but it was estimated to be in the same order as in the previously mentioned studies (6 passes, initial thickness $5.6 \mathrm{~mm}$, final thickness $1.9 \mathrm{~mm}$ ). On the other hand, Wauthier et al. [71] performed ASR on an IF steel using a relatively low total thickness reduction (around 30\%, single-pass). The effects of roll velocity ratio (from 1.1 to 1.45) were addressed and no rotation of rolling direction was implemented. $\gamma$ fiber components, as well as a significant $\{001\}<110>$ component, were obtained after rolling. This texture was softened upon annealing, by an increase of the random intensity at the expense of the $\{001\}<110>$ texture and the $\gamma$ fiber intensities. Higher roll velocity ratios led to weaker $\gamma$ fiber which is favorable for planar isotropy of the sheets. This softening of texture was in agreement with the results of Jin and Lloyd (e.g., [60]) obtained for ASR of AA6111. Another example of texture softening is observed in the work of Tamimi et al. [72]. They performed ASR on an IF steel to ascertain the effects of rolling direction reversal and total thickness reduction on the texture, microstructure and mechanical response of the material. Textures of CR samples had well-developed shear texture components, whereas ASR specimens (without inversion of rolling direction) had a softer texture 
with little prominent shear texture components. $r$ values of ASR specimens, determined only for RD, were slightly higher than CR specimens. Since only the $r_{0}$ value was determined, no conclusion can be drawn out for a formability advantage of ASR specimens.

Wroński et al. [67] performed ASR on low carbon steel using 25\% total thickness reduction and a low velocity ratio of 1.04. The texture evolution was simulated by a polycrystal model (isotropic elasto-plastic model, independent of strain rate) and compared to experimental results. Material properties were found to change due to the ASR effects on texture. ASR textures on the sheet surface were observed to be rotated around TD when compared to textures observed in CR. Orlov et al. [68] performed ASR on a Ti-stabilized IF steel, using 2 schedules of total reduction (66\% and $80 \%)$ with a reduction per pass of $30 \%$. The effects of roll speed ratio and rolling direction rotation around RD on the texture of the material were addressed. After rolling, they observed a strengthening of the $\gamma$ fiber, and increased yield stress. These effects were not so pronounced if a rolling reversal was employed. Upon recrystallization ([68], part II), the main difference between ASR and CR specimens remained the overall texture rotation of about $12^{\circ}$ around the TD axis observed in ASR specimens, inherited from the as-rolled condition. Additionally, the authors observed the RC component to be less pronounced in the ASR samples when compared to CR samples. Hence, $r_{m}$ values upon annealing were enhanced from 1.07 (CR) to 1.51 (ASR). The result is coherent with the fact that this texture component is detrimental for $r$ values [45]. In a recent study, Dhinwal et al. [73] performed single-pass ASR experiments on a low carbon steel, to determine the conditions for which the rolling texture can be transformed into a shear texture. They confirmed previous observations that a high reduction per pass (50\%) coupled with a roll speed ratio of 2 give rise to those texture components.

A different aspect of ASR was studied by Dong et al. [74]. The effect of strong plastic deformation by means of hot ASR on the precipitation of a $\mathrm{Ti}_{4} \mathrm{C}_{2} \mathrm{~S}_{2}$ in an IF steel was studied. In this case, the strain imposed by ASR was observed to enhance the precipitation of $\mathrm{Ti}_{4} \mathrm{C}_{2} \mathrm{~S}_{2}$. These precipitates are advantageous because they prevent the formation of small TiC precipitates, which occurs naturally in steels upon cooling, and has a detrimental effect on the growth of $\{111\}$ recrystallized grains. After ASR, a stronger $\gamma$ fiber texture with equal $\{111\}<112>$ and $\{111\}<110>$ components was formed. This should theoretically improve the material $r$ values.

Besides low carbon, other steels have been studied in the context of ASR. Stainless steels were studied by Barella and Mapelli [75] to assess the effect of ASR. They found improved anisotropy and r values, explained by the generation of more favorable textures throughout the sheet thickness. The roll speed ratio was 1.4. Amininejad et al. [76] performed ASR on a AISI304 stainless steel. They observed that the intensity of the recrystallization texture existing in the initial material decreased during rolling for thickness reductions up to $30 \%$. For higher reductions, the dynamic recrystallization occurred which led to an increase of the intensity of the recrystallization texture. Opposite trend was observed for the volume fraction of martensite, which increased for low strains but decreased after activation of the dynamic recrystallization. Nevertheless, samples deformed up to $40 \%$ retained their ductility while increasing yield and ultimate tensile strength. Chen et al. [77] studied a High-strength low-alloy (HSLA) steel processed by ASR with the intent of increasing its impact toughness. The authors obtained an improved impact toughness in the asymmetric hot rolled plate, due to the grain refinement, as well as a lower toughness anisotropy, in this case, due to the lower volume fraction of the RC texture component. Grydin et al. [35] studied ASR on a Dual-Phase steel. Besides observing the lower rolling force associated with ASR, they obtained improved texture components in the ASR specimens, namely the $\{110\} / / N D$ components, which were not observed in conventionally rolled samples. Twinning-induced plasticity (TWIP) austenitic steels were studied by Berrenberg et al. [78] and Brasche et al. [79]. Both studies contain evidence of rotation of textures around TD, as previously mentioned, which are dependent on rolling parameters, namely reduction per pass and speed ratio.

ASR is also used in steels for enhancing other properties, such as magnetic or electric properties. Sha et al. [80] used ASR for improved magnetic induction in steels. In this case, a strong recrystallization texture is desirable $(\{001\}<100>)$ and this was achieved by combining ASR and CR. Chen et al. [81] 
performed hot ASR to achieve such recrystallization texture more efficiently. Upon the rolling operation, the recrystallization texture component was in fact increased but lost after subsequent cold rolling operations. This seems expected in the context of texture evolution in steels.

\section{Microstructure Evolution}

The microstructure evolution of the material through the ASR process is associated with a grain refinement, due to the defragmentation of the grains under the action of the compressive and shear deformation. As a rule, the increase of the equivalent strain introduced by rolling increases the density of dislocations, which promotes the formation of dislocation cells. For higher values of strains, these are transformed into subgrains. This transformation has intermediate phases in which elongated grains or dislocations walls can be present and co-existing with equiaxed cells, before the formation of new subgrains. Initial investigations reported that grain refinement requires a large amount of deformation which leads to new small grains, equiaxed, with the size smaller than $2 \mu \mathrm{m}[50,53,82-85]$. For example, Figure 6 shows the evolution of the grain size of AlMg alloy processed by ASR with a total thickness reduction of $85 \%$. The initial material has an average grain size of about $25 \mu \mathrm{m}$ (Figure 6a) while after rolling, refined grains with a size of about $0.5 \mu \mathrm{m}$ are visible (Figure $6 \mathrm{~b}$ ). The process is sensitive to the material properties and rolling conditions.

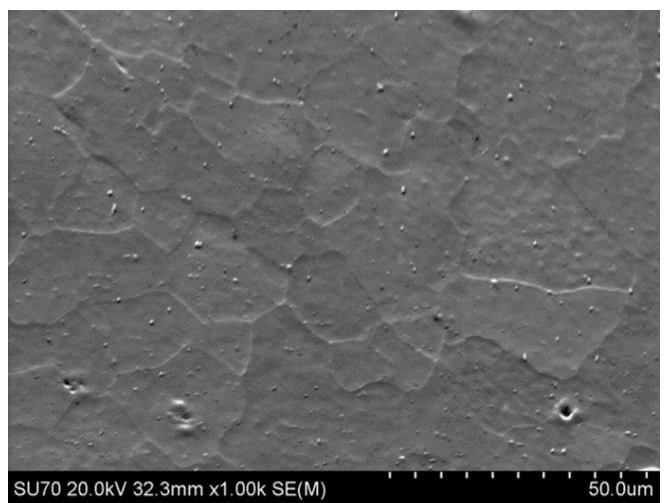

(a)

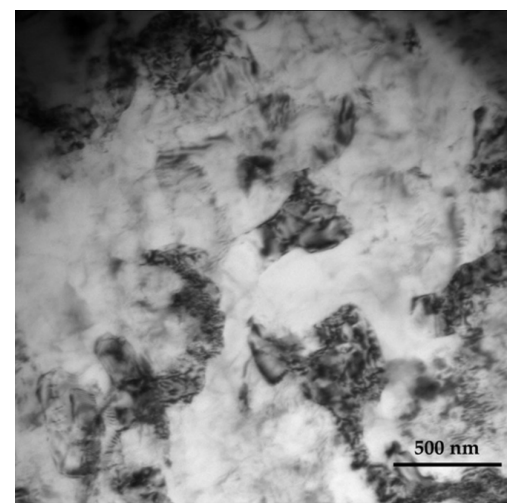

(b)

Figure 6. Grain size evolution through Asymmetric rolling (ASR): (a) initial grains of AA5182 before rolling observed by SEM (Scanning Electron Microscopy) and (b) new fine grains after ASR (85\% thickness reduction) observed by TEM (Transmission Electron Microscopy).

Recent studies of Wronsky and Bacroix $[21,86]$ show that division of the grains is strongly dependent on the shear deformation generated by the asymmetry of the process. They evaluated the effect of asymmetry imposed by the variation of rolls speed ratio in aluminum alloys in only one pass of rolling with a reduction of $36 \%$, and concluded that a minimal existence of asymmetry as low as 1.05 (where 1 corresponds to symmetry) leads to a change in microstructure and one pass is sufficient to produce significant grain refinement. Of course, the changes in microstructure are more pronounced for higher asymmetry. The same study shows that low asymmetry modifies the material only in the middle layer of the thickness. This can be useful for controlling the heterogeneity of the sheet. ASR with large thickness reduction leads to a homogeneous structure through the thickness. Small and medium reduction lead to heterogeneity between surfaces and center of the sheet [21,82].

The grain sizes after grain refinement, produced by the ASR in aluminum alloys and steels are presented in Table 2. Parameters of thickness reduction per pass, total reduction, number of passes and asymmetry ratio (than can be produced by speed, diameters or friction) are presented since they are the main factors of the process. 
Table 2. Overview of grain refinement produced by the Asymmetric rolling (ASR) for aluminum alloys and steels.

\begin{tabular}{|c|c|c|c|c|c|c|}
\hline Material & $\begin{array}{l}\mathbf{N}^{\circ} \\
\text { Passes }\end{array}$ & $\begin{array}{l}\text { Total } \\
\text { Reduction }\end{array}$ & $\begin{array}{l}\text { Asymmetry } \\
\text { Ratio }\end{array}$ & $\begin{array}{l}\text { Asymmetric } \\
\text { Rolling Grain Size }\end{array}$ & $\begin{array}{l}\text { Symmetric } \\
\text { Rolling Grain Size }\end{array}$ & Ref \\
\hline AA1xxx & 3 & $91.3 \%$ & 1.4 & $2 \mu \mathrm{m}$ & - & [82] \\
\hline AA1050 & 5 & $93.7 \%$ & 1.36 & $2 \mu \mathrm{m}$ & $2 \mu \mathrm{m}$ & [25] \\
\hline AA6061 & 1 & $36 \%$ & 1.5 & $4 \mu \mathrm{m}$ & $9 \mu \mathrm{m}$ & [21] \\
\hline AA5052 & 2 & $75 \%$ & $1: 4$ & $0.5 \mu \mathrm{m}$ & no refinement & [20] \\
\hline AA5754 & 10 & $88 \%$ & 2 & $1 \mu \mathrm{m}$ & - & [83] \\
\hline AA7050 & 10 & $75 \%\left(\sim 475^{\circ} \mathrm{C}\right)$ & 1.25 & $<0.5 \mu \mathrm{m}$ & - & [87] \\
\hline AA5182 & 2 & $50 \%$ & 1.36 & $20 \mu \mathrm{m}$ & - & [88] \\
\hline AA5182 & 6 & $90 \%$ & 1.36 & $0.3 \mu \mathrm{m}$ & - & [88] \\
\hline IF steel & 1 & $36.8 \%$ & 1.45 & $\begin{array}{l}8.7 \mu \mathrm{m} \text { (RD) } \\
5.8 \mu \mathrm{m}(\mathrm{TD})\end{array}$ & $\begin{array}{l}14.1 \mu \mathrm{m}(\mathrm{RD}) \\
8.4 \mu \mathrm{m}(\mathrm{TD})\end{array}$ & [71] \\
\hline IF steel & 3 & $60 \%$ & $1.15 / 1.3$ & $50 \mu \mathrm{m}$ & $80 \mu \mathrm{m}$ & [86] \\
\hline TWIP & - & $60 \%\left(\sim 1000^{\circ} \mathrm{C}\right)$ & $1.1 / 1.2 / 1.3$ & $\begin{array}{l}5 \mu \mathrm{m} \text { (surface) } \\
9 \mu \mathrm{m} \text { (center) }\end{array}$ & - & [89] \\
\hline Low Carbon Steel & 4 & $75 \%$ & $1: 4$ & $0.4 \mu \mathrm{m}$ & - & [90] \\
\hline Low Carbon Steel & 4 & $60 \%$ & 1.5 & $1.5 \mu \mathrm{m}$ & - & [72] \\
\hline $\begin{array}{l}\text { Low carbon } \\
\text { microalloyed steel }\end{array}$ & 1 & $50 \%\left(800^{\circ} \mathrm{C}\right)$ & $1: 2$ & $\begin{array}{l}0.92 \mu \mathrm{m} \text { (surface) } \\
1.09 \mu \mathrm{m} \text { (center) }\end{array}$ & $\begin{array}{l}1.02 \mu \mathrm{m} \text { (surface) } \\
1.44 \mu \mathrm{m} \text { (center) }\end{array}$ & [91] \\
\hline
\end{tabular}

Besides the grain refinement, grain boundary misorientation is an important effect of the ASR. As a general consequence, the volume fraction of high angle boundaries (HABs), (i.e., intragranular misorientation angle $>15^{\circ}$ ) increases when thickness reduction and/or the asymmetry ratio of the process increases. This is consistent with the effect on microstructure homogeneity across the thickness of the rolled sheet. The transition from low angle boundary (LABs) usually observed at low degree of deformation to high angle boundary observed for large strains depends on the material. Another important factor for the investigation of microstructure developed in ASR is the annealing heat treatment. Due to the high quantity of plastic work accumulated during the ASR rolling, the materials show a low ductility and a heat treatment is mandatory for recovering some ductility. Nevertheless, it is worth mentioning that the ASR can preserve the small size of the grains during annealing.

\subsection{Microstructure of Aluminum Alloys}

Starting with pure commercial aluminum, the work rapidly has been extended to more complex systems like 5000 and 6000 series were the interaction of dislocations with each other and solute atoms and precipitates makes the analysis of ASR more complicated.

Regarding pure aluminum, the work of Cui and Ohori [82] shows that ASR is much more indicated for grain refinement than CR. They studied the microstructure evolution in terms of grain refinement, grains and subgrains boundary misorientation and concluded that even for a smaller amount of thickness reduction (65.2\%) applied in ASR the grain refinement occurs while for a larger amount of thickness reduction $(91.3 \%)$ in CR it doesn't. They also pointed out that the grain refinement is directly correlated to the grain boundary misorientation distribution, particularly, the volume fraction of HABs increases linearly, while the volume fraction of LABs (between $2^{\circ}$ and $10^{\circ}$ ) decreases linearly. This study recommends annealing at maximum $150{ }^{\circ} \mathrm{C}$ or below to keep the small size of the grains $(\sim 2 \mu \mathrm{m})$. The work on pure commercial aluminum (AA1050) performed in our laboratory by Simões et al. [57] contradicts this in some ways. For example, the grain refinement was obtained for both CR and ASR (total thickness reduction $80 \%$ ) with a grain size of about $1-2 \mu \mathrm{m}$ after rolling and 5-7 $\mu \mathrm{m}$ after annealing at $250{ }^{\circ} \mathrm{C}$. The reason for increasing the annealing temperature is related to the improvement of ductility. In the study of Cui and Ohori [82], the mechanical properties after rolling 
were ignored, and consequently the annealing at $150{ }^{\circ} \mathrm{C}$ was evaluated only in terms of its effect on grain growth. However, the effect of ASR on grain refinement of pure aluminum seems to be sensitive to the processing routes. Another work on AA1050 performed in our laboratory by Kudrathon [92] shows that an annealing heat treatment at $280{ }^{\circ} \mathrm{C}$ for $1 \mathrm{~h}$ is favorable to retain the $1-2 \mu \mathrm{m}$ size of the grains. In this work, the material (different batch from the one used in the work of Simões et al.) was processed in 6 steps with an asymmetry factor of 3 and a total thickness reduction of $62 \%$.

Aluminum-magnesium alloys have been studied deeply in the last two decades. Jin and Lloyd [83] produced a grain refinement in AA5754 to the grain size of about $1 \mu \mathrm{m}$ by ASR using a total thickness reduction of $97 \%$ in 10 passes and an asymmetry factor of 2 . The obtained results are similar to other severe plastic deformation techniques such as ECAE (Equal channel angular extrusion) and DC (conventional direct-chill). They observed in this work that the Hall-Petch relationship is valid even for such small grains. Regarding the annealing procedure, they concluded that for maintaining the very fine grains the temperature should be below $275^{\circ} \mathrm{C}$. Between $275-400{ }^{\circ} \mathrm{C}$ the grain size increases to $5-10 \mu \mathrm{m}$, and above $400{ }^{\circ} \mathrm{C}$ the significant grain growth about $20-25 \mu \mathrm{m}$ is observed. They studied the same material in different ASR condition, namely, 56\% total thickness reduction in 2 passes applied in symmetric rolling, asymmetric rolling continuous (case 1 from Figure 4) and reverse (one of the cases 2-4 from Figure 4; not specified in the paper) [50]. For 56\% reduction in 2 passes, only a small variation in the grain size can be observed in the micrographs presented in this paper, but not a grain refinement. The asymmetric rolling continuous (i.e., case 1 from Figure 4) with higher asymmetry (i.e., speed ratio 2) is the one who promote finer grain fragments and higher volume fraction of HABs. The symmetric and asymmetric reverse rolling led to a similar degree of fragmentation of the grains for this reduction. It seems that for $5 X X X$ aluminum alloys the total reduction is essential. Our previous work on AA5182 shows the same trends, namely for $50 \%$ total thickness reduction in 2 passes almost no grain refinement is observed and for the same material rolled up to $90 \%$ the grain refinement led to very fine grains about $0.3 \mu \mathrm{m}$ [88]. Very fine equiaxed grains were obtained by Loorentz and Ko [20] by ASR in only two passes with a 50\% reduction per pass in AA5052. In this case, a very high asymmetry was introduced by the rolls speed ratio of 4 . This seems to be the reason for the grains defragmentation since the same results were not obtained for sample processed without asymmetry conditions.

Aluminum-Magnesium-Silicon alloys, the 6xxx series, are other alloys largely investigated due to their vast applications in the automotive industry. Jin and Lloyd [60] studied ASR effect on AA6111 using four levels of rolls speed ratio for a total thickness reduction of $50 \%$ in two passes and low friction conditions (friction coefficient $\sim 0.06$ ). The grain size reduction depended on the type of rolling, being higher for a higher asymmetry ratio (equal to 4). Although grain refinement occurred, since the initial material was comprised of coarse grains in the range of $100-1000 \mu \mathrm{m}$, the average grain size after rolling remained of about $\sim 40 \mu \mathrm{m}$ and $\sim 30 \mu \mathrm{m}$ for symmetric and asymmetric conditions, respectively. Wronski and Bacroix [21] studied the microstructure evolution in AA6061 processed by a single pass of thickness reduction (36\%) in symmetric and asymmetric conditions (asymmetry factors between 1.05-1.5) and high friction conditions (no lubrication). As mentioned before, in the introduction, they confirmed that 1 pass is sufficient to produce grain refinement particularly if the asymmetry is above 1.5. For asymmetry ratio below 1.5, the grain refinement takes place only in the mid-layer of the sheet. It is worth noting that in this paper the average grain size of the initial material is not indicated, and thus it is impossible to analyze the degree of grain size reduction. However, comparing the grain size reduction in case of symmetric and asymmetric rolling (i.e., $9 \mu \mathrm{m}$ and $4 \mu \mathrm{m}$, respectively) it seems that the conditions proposed by Wronski and Bacroix are more efficient for refinement of the grains than the one presented by Jin and Lloyd for 6XXX series. Moreover, as in the case of the 5XXX series, the annealing heat treatment is necessary. For both alloys, the annealing temperatures are situated in the solubilization zone, but the annealing time is different. Thus, Jin and Lloyd [60] used a very short annealing time of $1 \mathrm{~min}$ at $560{ }^{\circ} \mathrm{C}$, while Wronski and Bacroix used annealing time of $1 \mathrm{~h}$ at $500{ }^{\circ} \mathrm{C}$. It should be noted that no grain growth has been observed in both cases. Recently, Ren et al. [63] studied the microstructure evolution of AA6016 processed by twin-roll casting followed by symmetric 
and asymmetric rolling. They used two asymmetries, namely speed ratio 1.4 and 1.8 and the rolling schedule represented in case 3 from Figure 4, with a reduction per pass equal to $0.2 \mathrm{~mm}$. This reduction per pass is extremely low resulting in a very high number of passes (28 passes) taking into consideration that material was rolled from $6.5 \mathrm{~mm}$ to $1 \mathrm{~mm}$. We believe that there is an error and the reduction per pass was $20 \%$ that leads to 8 passes. After rolling, the samples were annealed at $330{ }^{\circ} \mathrm{C}$ for different periods of time between 0 to $60 \mathrm{~min}$ following the degree of recrystallization. After rolling and partial recrystallization (35\%), grain refinement is observed in all rolling schedules with the final grain size about $9 \mu \mathrm{m}$ and $12 \mu \mathrm{m}$ for CR and ASR respectively. It should be mentioned that after complete recrystallization the average grain size increased for sample processed symmetrically and reached the value of $19.5 \mu \mathrm{m}$ and it was retained for ASR $(12 \mu \mathrm{m})$. These effects are associated with the discontinuous recrystallization in case of CR and continuous recrystallization in case of ASR.

Ma et al. studied the effect on ASR (asymmetry factor 1.25) on AA7050 with a particular interest in the influence of thickness reduction per pass [87]. The thickness reductions from $20 \mathrm{~mm}$ to $5 \mathrm{~mm}$ were achieved in 1, 2, 4 and 10 passes with the corresponding reduction per pass of $75 \%, 50 \%, 29 \%$ and $13 \%$. The sheets were preheated before rolling at $430^{\circ} \mathrm{C}$ for $1 \mathrm{~h}$. After rolling the samples were annealed at $475{ }^{\circ} \mathrm{C}$ for $1 \mathrm{~h}$. The grain refinement was more pronounced for lower reduction per pass, with a difference in average grain size of about $5 \mu \mathrm{m}$ between the lowest and highest reduction per pass. Thus, the grain size was reduced from $100-150 \mu \mathrm{m}$ in the initial material, to $13-18 \mu \mathrm{m}$ after rolling. At the same time, the fraction of HABs was much higher for low reduction per pass compared to a high reduction per pass, being more than double. This study recommends the use of small reduction per pass since it promotes grain refinement and homogeneity of microstructure through the entire thickness of the sheet

\subsection{Microstructure of Steels}

ASR process on single-phase steels, such as low carbon steel and IF steels, have been investigated extensively. An important contribution to this field about it is the work of Orlov et al. [93]. They studied the effects of the initial thickness $(6.5$ and $16.5 \mathrm{~mm})$, the total reduction $(66 \%$ and $88 \%)$ the asymmetry factor (1.3, 1.6 and 2) and the rolling route (case 1 and 3 from Figure 4) while keeping the reduction per pass constant at $30 \%$. TEM observations after rolling showed the development of microbands aligned with the rolling direction and shear bands rotated at $35^{\circ}$ angle with the rolling direction. Their results showed that the distance between microband as well as their width depended on the type of rolling. The distance between microbands decreased for ASR compared to conventional rolling. The interaction of two sets of deformation bands led to a fragmentation of the dislocation substructure, with well-defined dislocation walls and low dislocation densities inside of cells which further transformed in new fine grains. From the TEM micrographs, the size of the grains seems to be around $0.5-1 \mu \mathrm{m}$ for ASR and around 1-2 $\mu \mathrm{m}$ for CR. As in the case of aluminium alloys, the important factor is the annealing heat treatment. Thus, Orlov et al. continued their work with the investigation of the annealing effects after rolling using a range of temperatures between $500{ }^{\circ} \mathrm{C}$ and $750{ }^{\circ} \mathrm{C}$ [68]. The EBSD analyses of CR and ASR (case 1) samples after rolling showed the grain refinement with a higher percentage of HABs for ASR (19\%) than conventional (13\%), but the dominant feature was the LABs. After annealing at all temperatures the percentage of HABs increased and became similar for both types of rolling. However, the full recrystallization and grain growth occurred above $700{ }^{\circ} \mathrm{C}$ for both routes (i.e., ASR and CR), being faster for ASR than for CR. Thus, they recommend the annealing temperature of $600{ }^{\circ} \mathrm{C}$ for $30 \mathrm{~min}$ to obtain the improved mechanical behavior.

Wauthier et al. [71] used IF steel to study the effect of asymmetry ratio (between 1.10-1.45) in only one pass thickness reduction. Although the "roll gap" and the friction conditions (roughness of $0.3 \mu \mathrm{m}$ for both rolls) were maintained the same, the asymmetry of the rolls speed ratio led to different thickness reductions (32.2-36.8\%) or, in other words, led to different amounts of equivalent strain. The microstructure formed after rolling showed the fragmentation of the grains being higher for higher speed ratio of the process. This is related to the contribution of the shear deformation generated by the 
asymmetry. The refinement of the grains was observed for all the samples. However, the grains were elongated in the rolling direction showing smaller grains for higher asymmetry with a size between 8.7-14.1 $\mu \mathrm{m}$ and 5.8-8.4 $\mu \mathrm{m}$ in $\mathrm{RD}$ and TD respectively. The annealing at $700{ }^{\circ} \mathrm{C}$ led to grain growth with the new grain sizes in the rage of 18.7-21.5 $\mu \mathrm{m}$ and 16.2-18.1 $\mu \mathrm{m}$ in RD and TD respectively. Figure 7a) shows the evolution of grain size with the degree of asymmetry. If we define the grain growth factor as the ratio between the grain size after and before heat treatment, it can be observed that the size of the grains increased by a factor of 2 for asymmetry of 1.45 , and by a factor of 1.5 for all other asymmetries as can be seen in Figure $7 b$ ).

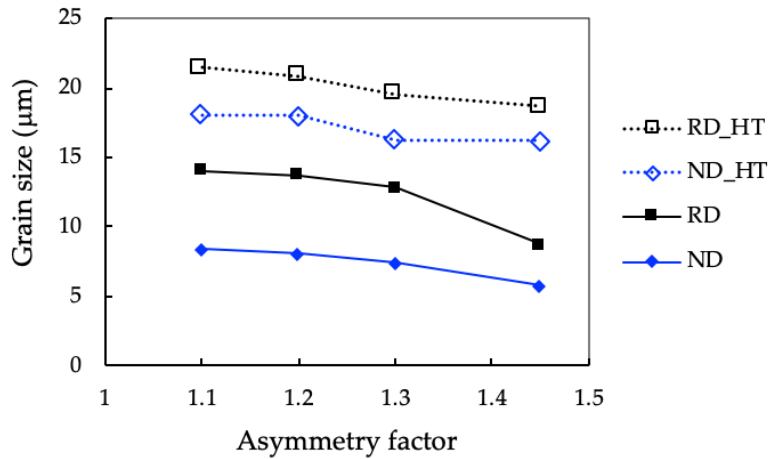

(a)

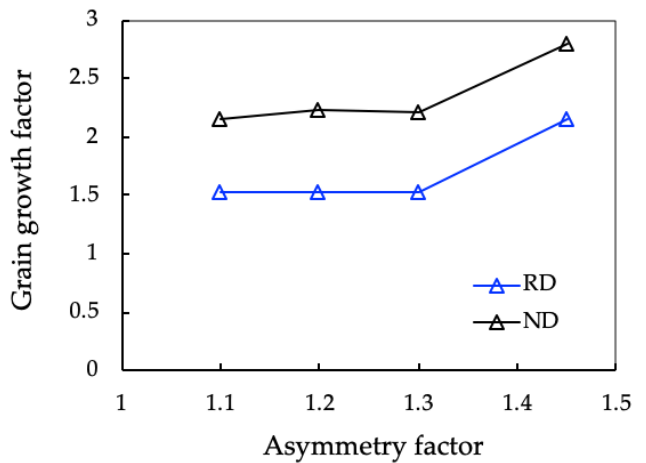

(b)

Figure 7. Grain refinement in function of asymmetry factor: (a) grain size and (b) grain growth by annealing at $700{ }^{\circ} \mathrm{C}$ for $30 \mathrm{~min}$. Data from [71].

Lapovok et al. [70] investigated ASR of IF steel using one idle roll in six passes and obtained grain refinement with grain size between $2-5 \mu \mathrm{m}$ for ASR and CR. Moreover, they observed that ASR reversed (case 3 from Figure 4) led to a more homogeneous structure.

Tamimi et al. [72] performed ASR in IF steel to study the effect of processing routes. The material was rolled to $60 \%$ total thickness reduction in 4 passes following routes 1 and 3 from Figure 4 . For comparison, additional samples were processed by CR. The microstructure of CR specimens showed dislocation cells elongated in RD direction, while equiaxed cells were observed for ASR. The annealing heat treatment used in this work was $550{ }^{\circ} \mathrm{C}$ for $1 \mathrm{~h}$ and allowed the preservation of the grain size between $1-2 \mu \mathrm{m}$.

ASR of low carbon steel has been investigated by Wroński and Bacroix [86] in 2016. They studied the effect of thickness reduction (in 1 and 3 passes) and process asymmetries (i.e., asymmetry factor $1.05,1.1$ and 1.3) and symmetry. For thickness reduction above $50 \%$, the grain refinement occurred, being more accentuated and uniformly distributed throughout the entire thickness for ASR. In this work, the microstructure evolution was analyzed using the image quality factor (IQ) which showed that the shear bands were located inside the grains in case of CR and near the grain boundary with a possibility of propagation across it to other grains in case of ASR. In addition, Kernel Average Misorientation (KAM) parameter was used for the study of heterogeneity inside of grains. A higher value of KAM was observed near the grain boundaries for all rolled samples. For higher asymmetry factor, the density of high KAM was increased. The main conclusion of this study was that is possible to obtain a homogeneous material with small grains by applying small thickness reductions.

Cai et al. [91] applied ASR process to commercial low carbon microalloyed steel. The process occurred at $800{ }^{\circ} \mathrm{C}$ and the samples were heated to $850{ }^{\circ} \mathrm{C}$ before rolling. Both types of rolling (i.e., $\mathrm{CR}$ and ASR) produced ultra-fine grains of ferrite and some martensite. The average grain size obtained in ASR was about $1 \mu \mathrm{m}$ and was uniformly distributed through the thickness. In symmetric rolling the grain size was smaller at the surface $(1.02 \mu \mathrm{m})$ and larger in the center $(1.44 \mu \mathrm{m})$. Regarding the misorientation distribution of the grains, a percentage of HABs in the center and surface in ASR was almost the same, while for $C R$ these values varied being lower in the center and higher in the 
surface layers. This study concluded that ASR combined with dynamic transformation can be used to produce more homogeneous microstructure and texture through the thickness of the sheet which allow to control the plastic instability.

Dhinwal et al. [73] studied the effect of RPP in a range of $20-75 \%$ in one pass for extra-low carbon steel, asymmetry factor between 1 to 2 at room temperature and concluded that a faster grain fragmentation occurred in ASR compared to CR due to the strong shear component. They observed also that the small size of the grains $(\sim 3 \mu \mathrm{m})$ was better preserved during a very short time of annealing (up to $120 \mathrm{~s}$ ) in the case of ASR. This was associated to lower apparent activation energy to initiate recrystallization in case of ASR compared to $C R$, as a results of more heterogeneous microstructure and stored energy distribution developed in ASR.

Hamad and Ko [90] made a meticulous investigation of the annealing of low-carbon steel processed by ASR. The material with an initial grain size of $100 \mu \mathrm{m}$ and $4 \mathrm{~mm}$ thickness was rolled in 4 passes to a total reduction of about $75 \%$ with a high asymmetry factor of 4 . The range of annealing temperature was between $425{ }^{\circ} \mathrm{C}$ and $625^{\circ} \mathrm{C}$ and the annealing time was $1 \mathrm{~h}$. The process led to a grain refinement size of about $0.4 \mu \mathrm{m}$. The annealing temperatures of up to $475{ }^{\circ} \mathrm{C}$ preserved the ultrafine ferrite grains produced by ASR. Around $500{ }^{\circ} \mathrm{C}$ the recrystallization process is initiated, and the increase of grain size was observed. The fraction of HAB's after annealing at $475{ }^{\circ} \mathrm{C}$ was around $60 \%$ and slightly increased with the annealing temperature. This increase was due to the formation of coarse grains, which occurred for temperatures above $525^{\circ} \mathrm{C}$.

TWIP steel deformed by ASR was studied by Ma et al. [89]. The effect of heating temperature before rolling (i.e., $1100{ }^{\circ} \mathrm{C}$ and $970{ }^{\circ} \mathrm{C}$ ), the effect of temperature of rolling $\left(1050{ }^{\circ} \mathrm{C}, 1000{ }^{\circ} \mathrm{C}, 930^{\circ} \mathrm{C}\right.$ and $\left.860^{\circ} \mathrm{C}\right)$, asymmetry ratio $(1,1.1$ and 1.2$)$ and total reduction $(60,40$ and $20 \%$ ) were the parameters investigated. The results showed a microstructure gradient between the surfaces and the center of the sheet. Ma et al. optimized the rolling conditions in such a way that the grain refinement occurred, leading to a comparable size of the grains on the surfaces and in the center, $5 \mu \mathrm{m}$ and $9 \mu \mathrm{m}$, respectively. High asymmetry factor (1.2) and high total reduction (60\%) were the main factors for the improvement of microstructure and mechanical behavior of TWIP steel. Also, the temperature and the velocity of the process were important since are directly correlated to the strain rate sensitivity of the material. This work indicates that the temperature in the end of the rolling should be higher than $900{ }^{\circ} \mathrm{C}$ and the lower circumferential speed should be above $1 \mathrm{~m} / \mathrm{s}$. The static nucleation of the grains occurred at the end of the rolling process for temperatures above $900{ }^{\circ} \mathrm{C}$ and was the only factor contributing to the formation of the fine recrystallized grains, since the dynamic recrystallization did not occur for the employed circumferential speed. Regarding the influence of the total thickness reduction, the temperature at the end of rolling was $830^{\circ} \mathrm{C}$ and at this temperature partial recrystallization occurred only for $60 \%$ reduction.

ASR of TWIP steel has been investigated also by Berrenberg et al. [78] at room temperature. They studied the effect of reduction per pass and the total reduction for an asymmetry factor of 2 . For comparison, CR was also performed. For low total thickness reduction (14\%), the microstructure evolution was very similar for both types of rolling but it became different for higher total thickness reduction. The grains became elongated and aligned with the rolling direction. In TWIP steels, during plastic deformation occurs the formation of deformations twins. The twins density increases with increasing thickness reduction, also being higher for ASR. In addition, after CR only primary twins were observed, while after ASR secondary twins were also observed. The presence of the secondary twins, which were formed as a consequence of the higher total strain and a more complex deformation state than in case of $C R$, seems to be beneficial for the grain refinement. This study concluded that more refined microstructure can be produced by ASR compared to CR, but no ultrafine grains (smaller than $1 \mu \mathrm{m}$ ) were obtained. 


\section{Mechanical Behavior}

Mechanical behavior of materials processed by ASR was not, until recently, frequently explored in literature, especially when considering the potential benefits of this technology in sheet metal forming operations. Technical difficulties in implementing the process using recommended parameters, such as high friction or high thickness reduction per pass, in a laboratory setting entail the usage of industrial-grade equipment, not readily available. On the other hand, industries were firstly interested in assessing ASR benefits on the rolling process itself, such as strip curvature, rolls service life, and rolling power [12,94-97].

\subsection{Aluminum Alloys}

The authors have been studying the effect of ASR on the mechanical behavior of aluminum alloys [25,57,88,98] and steels [99] since 2008. The main results focus on tensile and shear response, and their relation with texture and microstructural aspects, as well as alloying elements, when applicable.

Pure aluminum is a frequently studied material in plastic deformation processes and ASR studies, as it allows the isolation of texture, grain size and morphology effects from other factors such as alloying elements (forming solutes or precipitates). Simões et al. performed asymmetric rolling of an $8 \mathrm{~mm}$ thick AA1050 using speed ratio of 1.36 and a 50\% reduction per pass down to $0.65 \mathrm{~mm}$, to assess the effect of ASR on its mechanical response [57]. TD rolling reversal, corresponding to case 2 in Figure 4, was implemented and a CR schedule was performed for comparison. Tensile and shear tests on the RD were performed before and after annealing at $250{ }^{\circ} \mathrm{C}$ for $2 \mathrm{~h}$. While after rolling the yield strength of ASR and CR specimens was similar, upon annealing, the yield strength of ASR specimens remained much higher than CR specimens. Ultimate tensile strength was shown to increase visibly whereas ductility decreased as shown in Figure 8. Figure 9 shows that the material response to a simple shear test was similar among ASR and CR specimens.

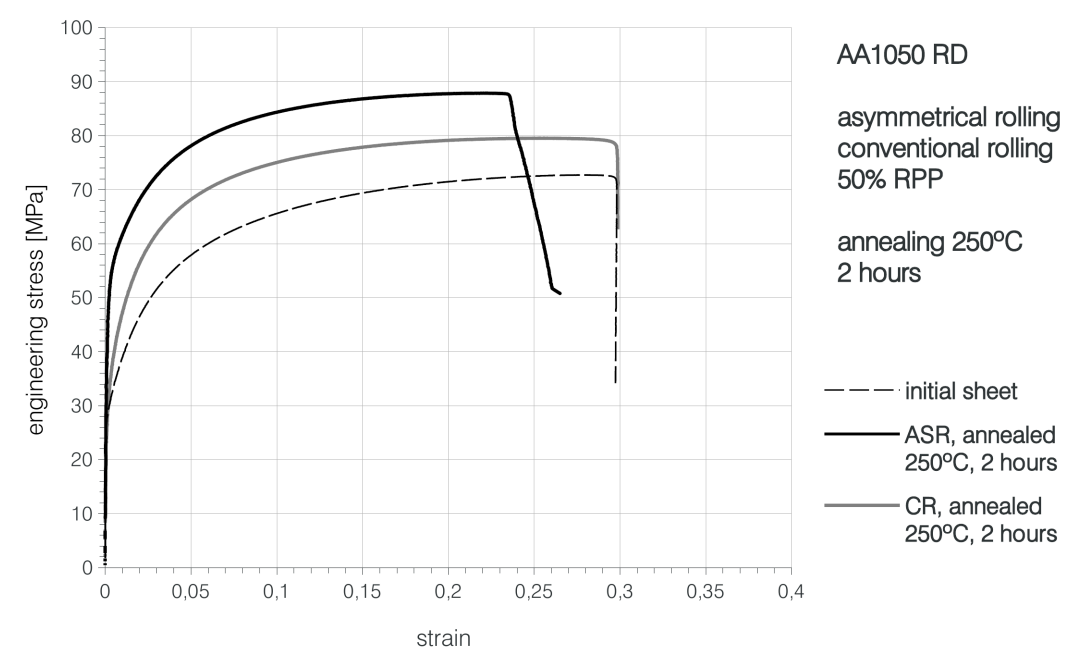

Figure 8. RD tensile tests of rolled (50\%RPP) and annealed $\left(250{ }^{\circ} \mathrm{C}\right.$ for $\left.2 \mathrm{~h}\right)$ specimens. Comparison between ASR and CR (adapted from [25] with permissions from authors, 2020). 


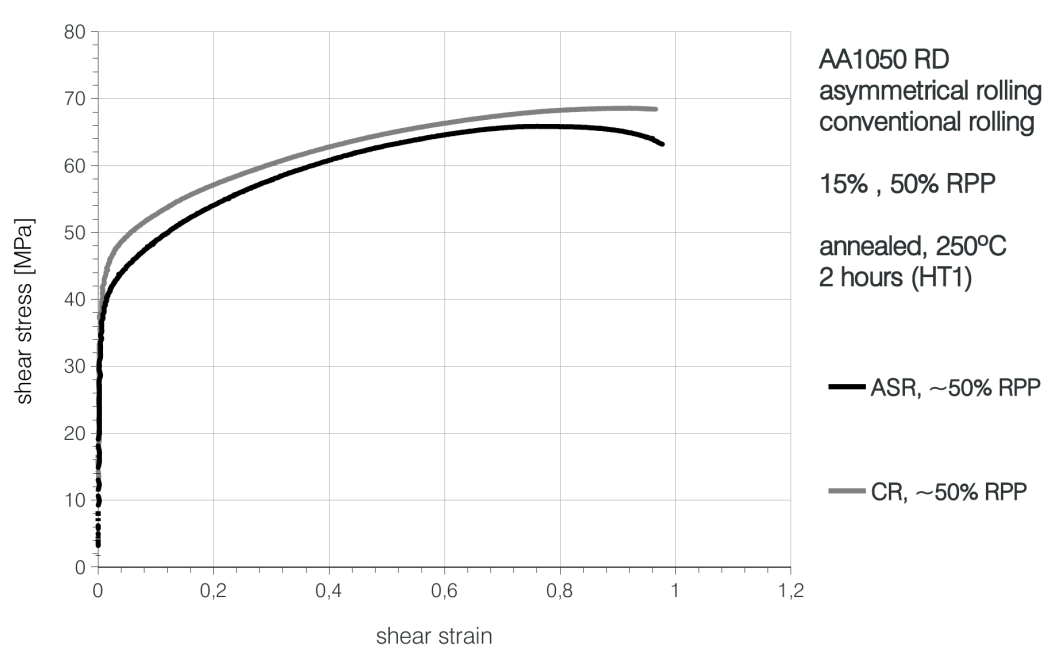

Figure 9. RD shear tests of rolled (50\%RPP) and annealed $\left(250^{\circ} \mathrm{C}\right.$ for $\left.2 \mathrm{~h}\right)$ specimens. Comparison between ASR and CR (adapted from [25] with permissions from authors, 2020).

ASR was confirmed to have the potential to enhance mechanical properties of sheets, though further optimizations regarding rolling routes were deemed necessary. Pure aluminum was also the focus of the work by Jiang et al. [19]. They used ASR to attain grain refinement. They implemented high friction conditions, but the speed ratio was not clarified. A significant improvement in the ultimate tensile strength of ASR specimens when compared do CR specimens, especially for the highest thickness reduction level was obtained, although at the expense of ductility.

As mentioned before, aluminum alloys 5XXX and 6XXX are studied in the scope of ASR because they have direct industrial application, and hence can readily display potential ASR advantages. In the previously mentioned study of Jin and Lloyd [83], the grain refinement obtained led to an improved compromise between strength and ductility, explained by the mixture of grain sizes $(10 \mu \mathrm{m}$ and smaller). Bintu et al. [88] studied the effect of ASR on the mechanical response of an AA5182 alloy, to increase the strain rate sensitivity of this material. Reverse rolling was used to attain shear textures more efficiently. The strain rate sensitivity was significantly affected only for the highest total thickness reduction $(90 \%)$. The annealing heat treatment showed a strong influence on the yield stress with an increase for ASR specimens and a decrease for CR specimens. This unusual behavior was associated with the differences of the microstructure formed during ASR and CR and the way in which the free solutes and the clusters contribute to the material strengthening. Kraner et al. [59] performed ASR on an AA5454 alloy with roll speed ratio of 1.0 (CR), 1.5 and 2.0, and two levels of reductions- $33 \%$ and $44 \%$ in a single pass. Mechanical properties were evaluated by tensile tests. No significant differences were found between specimens rolled with different methods or thickness reductions, before and after annealing. Results of the non-conventional processing route by Ren et al. [63] on a AA6016 alloy in terms of mechanical response are also worth noting, as they show an increase in yield stress and ductility, for the sample rolled with a 1.8 speed ratio. This was attributed to the combined effects of texture and grain refinement. In a later work also on a AA6016 alloy, Ren et al. [66] observed that an increase of annealing time is not recommended since it decreased the ultimate tensile strength and hardness while the ductility seemed to become stabilized. Ren et al. [100] performed ASR combined with thermal treatments on a AlMgSi aluminum alloy.After the complete processing route-including pre-treatment, ASR and natural ageing - they observed higher fractions of the $\operatorname{RC}(\{001\}<110>)$ and rotated Goss $(\{011\}<110>)$ components, attributed to the higher imposed shear strains. In conjunction with the impact of ASR and aging treatment on the microstructure, the authors obtained a significant improvement of yield and ultimate tensile strength, with ductility comparable to or higher than the conventional processing route. 


\subsection{Steels}

Regarding IF steel, the work of Lapovok et al. [70] described before showed that the ultimate tensile strength and ductility were not changed significantly through ASR. This was explained by the low level of shear strains induced by the setup. The work of Tamimi et al. [72] showed that the tensile stress depended on total thickness reduction and the strain path of the rolling. Namely, for low thickness reductions the tensile stress was higher for ASR specimens compared to those of CR, but the trend was reversed for higher reductions. The results were related to the microstructure and texture evolution. The work of Grydin et al. [35] on low carbon steel, showed an increase of tensile strength of more than $50 \%$ for ASR and CR in only one pass, being higher for ASR, while the ductility decreased drastically to values about $2-3 \%$. They concluded that the texture formed during the process was beneficial for the mechanical properties and deep drawing. Berrenberg et al. [78] studied the mechanical behavior of TWIP steel processed by ASR and CR. The tensile response showed minor differences between both types of rolling. A higher yield stress level was observed for ASR specimens which as expected was associated with a decrease in the respective elongation until necking. These results were associated to the microstructure evolution since the textures of CR and ASR specimens were similar. Another work on ASR in TWIP steel was done by Brasche et al. [79] who tried to optimize the strength-ductility combination. After ASR, they observed a microstructure refinement, attributed to the additional shear strain imposed, which guaranteed a high yield strength. Ductility was reported to increase as an effect of suppressed twinning activity at high-temperature rolling which favored the formation of deformation twins during plastic deformation after rolling. Improved both strength and ductility demonstrated the advantage of the ASR processing route.

\section{Conclusions}

ASR was shown to generate shear texture components, obtained from previous deformation textures by adequate rotation around TD. This rotation can be achieved effectively by controlling the equivalent strain of rolling combined with proper rotation of the sheet around RD or ND between each rolling pass, namely reverse rolling. These texture components were shown to contribute to the effective improvement of the anisotropy of sheets, and hence to increased formability.

ASR processing can be coupled with thermal treatments to extend their current reach in terms of material properties enhancement, as was demonstrated with heat-treatable aluminum alloys. The stability of shear texture components, as well as the preservation of sub-size grains upon heat treatment, is noticeable.

The set of additional parameters available in ASR provides enhanced control of material structure and texture, meaning it is possible to obtain materials with the desired homogeneity of grain size and texture. The mechanical behavior of asymmetrically rolled aluminum alloys is shown to improve significantly by the combined effects of texture, grain size and morphology, and thermal treatments. The processing of steels, including IF, TWIP or stainless steels was also shown to have much potential for improvement using ASR. Nevertheless, those process parameters are numerous and interactive and even can change continuously during the process as a consequence of the conditions imposed (for example, the friction conditions). This has been shown to cause difficulties in defining improved processing routes using ASR towards those objectives and seems to remain one of its main obstacles to wider industry-level adoption.

Author Contributions: Conceptualization, investigation, writing-original draft preparation, G.V. and F.S.; writing-review and editing, M.B. All authors have read and agreed to the published version of the manuscript.

Funding: GV and MB acknowledge support from the Operational Program for Competitiveness and Internationalization, in its FEDER/FNR component, and the Portuguese Foundation of Science and Technology (FCT), in its State Budget component (OE), through projects POCI-01-0145-FEDER-032362 (PTDC/EME-ESP/32362/2017), POCI-01-0145-FEDER-032466 (PTDC/EME-ESP/32466/2017), CENTRO-01-0145 -FEDER-022083, UIDB/EMS/00481/2020 and UIDP/00481/2020-FCT. FJPS acknowledges the Portuguese Foundation of Science and Technology (FCT) and Centro2020 through the following Projects: UIDB/04044/2020, UIDP/04044/2020 and PAMI - ROTEIRO/0328/2013 (N 022158). 
Conflicts of Interest: The authors declare no conflict of interest.

\section{Abbreviations}

The following abbreviations are used in this manuscript:

$\begin{array}{ll}\text { ASR } & \text { Asymmetric rolling } \\ \text { CR } & \text { Conventional rolling } \\ b c c & \text { body-centered cubic } \\ f c c & \text { face-centered cubic } \\ h c p & \text { hexagonal close-packed } \\ \text { ND } & \text { normal direction } \\ \text { RD } & \text { rolling direction } \\ \text { TD } & \text { transverse direction } \\ \text { RC } & \text { rotated cube } \\ \text { TWIP } & \text { twinning-induced plasticity } \\ \text { IF } & \text { interstitial-free } \\ \text { HSLA } & \text { high-strength low-alloy } \\ r & \text { anisotropy coefficient } \\ \text { LABs } & \text { low angle boundaries } \\ \text { HABs } & \text { high angle boundaries } \\ \text { RPP } & \text { thickness reduction per pass } \\ \text { KAM } & \text { Kernel Average Misorientation parameter }\end{array}$

\section{References}

1. Sachs, G.; Klingler, L.J. The flow of metals through tools of circular contour. J. Appl. Mech. 1947, 14, 88.

2. Holbrook, R.L.; Zorowski, C.F. Effects of Nonsymmetry in Strip Rolling on Single-Roll Drive Mills. J. Eng. Ind. 1966, 88, 401-408. [CrossRef]

3. Johnson, W.; Needham, G. Further experiments in asymmetrical rolling. Int. J. Mech. Sci. 1966, 8, 443-455. [CrossRef]

4. Zorowski, C.; Shutt, A. Analysis of the Load and Torque Characteristics of Single-Roll Drive Mills; International Research in Product Engineering ASME: Pittsburgh, PA, USA, 1963; p. 380.

5. Johnson, W.N.G. An experimental study of asymmetrical rolling. In Applied Mechanics Convention; Institution of Mechanical Engineering: Cambridge, UK, 1966.

6. Richelsen, A. Elastic-plastic analysis of the stress and strain distributions in asymmetric rolling. Int. J. Mech. Sci. 1997, 39, 1199-1211. [CrossRef]

7. Richelsen, A.B. Numerical analysis of asymmetric rolling accounting for differences in friction. J. Mater. Process. Technol. 1994, 45, 149-154. [CrossRef]

8. Skorokhodov, V.; Polyakov, M.; Skorokhodov, S. Study of Metal Flow During Asymmetric Rolling. ISSLEDOVANIE TECHENIYA METALLA PRI NESIMMETRICHNOI PROKATKE. Izv. Vyss. Uchebnykh Zaved. Chernaya Metall. 1977, 73-76.

9. Skorokhodov, V.; Polyakov, M.; Skorokhodov, S. Metal flow during asymmetric rolling. Steel USSR 1978, 7, 457-458.

10. Pavlov, I.; Karelin, F.; Portnaya, Z. Relationship between the geometrical parameters of blanks and finished products with asymmetric rolling. Russ. Metall. 1985, 3, 100-104.

11. Potapkin, V.; Satonin, A.; Dobronosov, Y. Deformation of metal in asymmetric rolling of thin strips. Russ. Metall. 1987, 62-66.

12. Gorelik, V.; Nalcha, G.; Rudnev, A.; Klimenko, I.; Feofilaktov, A. Improvement of service properties of plates by utilization of asymmetric rolling. Steel USSR 1991, 11, 41-44.

13. Gorelik, V.; Klimenko, I. Classification and analysis of strip rolling with asymmetric deformation zone. Izv. Akad. Nauk. SSSR Metall. 1997, 3, 34-42.

14. Tibar, H.; Jiang, Z. Improving Thin Strip Profile Using Work Roll Cross and Work Roll Shifting Methods in Cold Strip Rolling. Int. J. Met. 2017, 2017, 1-10. [CrossRef] 
15. Aljabri, A.; Jiang, Z.; Wei, D. Analysis of thin strip profile by work roll crossing and shifting in asymmetrical cold rolling. Int. J. Mod. Phys. B 2015, 29, 1540032. [CrossRef]

16. Lee, J.; Lee, D. Shear texture development and grain refinement in asymmetrically rolled aluminum alloy sheets: Effects of shear combinations. In Ultrafine Grained Materials III; Wiley: Charlotte, NC, USA, 2004; pp. 303-308.

17. Sidor, J.; Miroux, A.; Petrov, R.; Kestens, L. Controlling the plastic anisotropy in asymmetrically rolled aluminium sheets. Philos. Mag. 2008, 88, 3779-3792. [CrossRef]

18. Lee, J.K.; Lee, D.N. Texture control and grain refinement of AA1050 Al alloy sheets by asymmetric rolling. Int. J. Mech. Sci. 2008, 50, 869-887. [CrossRef]

19. Jiang, J.; Ding, Y.; Zuo, F.; Shan, A. Mechanical properties and microstructures of ultrafine-grained pure aluminum by asymmetric rolling. Scr. Mater. 2009, 60, 905-908. [CrossRef]

20. Ko, Y.G. Microstructure evolution and mechanical properties of severely deformed Al alloy processed by differential speed rolling. J. Alloy. Compd. 2012, 536, S122-S125. [CrossRef]

21. Wronski, S.; Bacroix, B. Microstructure evolution and grain refinement in asymmetrically rolled aluminium. Acta Mater. 2014, 76, 404-412. [CrossRef]

22. Yu, H.L.; Lu, C.; Tieu, A.K.; Li, H.J.; Godbole, A.; Zhang, S.H. Special rolling techniques for improvement of mechanical properties of ultrafine-grained metal sheets: A review. Adv. Eng. Mater. 2016, 18, 754-769. [CrossRef]

23. Wroński, S.; Wierzbanowski, K.; Wroński, M.; Bacroix, B. Three dimensional analysis of asymmetric rolling with flat and inclined entry. Arch. Metall. Mater. 2014, 59, 585-591. [CrossRef]

24. Feng, Y.; Liu, W.; Yang, T.; Du, F.; Sun, J. Theoretical and experimental analysis of the deformation zone and minimum thickness in single-roll-driven asymmetric ultrathin strip rolling. Int. J. Adv. Manuf. Technol. 2019, 104, 2925-2937. [CrossRef]

25. Simões, F.J.P. Asymmetrical Rolling of an Aluminum Alloy 1050. Ph.D. Thesis, University of Aveiro, Aveiro, Portugal, 2008.

26. Halloumi, A.; Desrayaud, C.; Bacroix, B.; Rauch, E.; Montheillet, F. A simple analytical model of asymmetric rolling. Arch. Metall. Mater. 2012, 57, 425-435. [CrossRef]

27. Halloumi, A.; Desrayaud, C.; Montheillet, F. A simple modeling of asymmetric rolling. AIP Conf. Proc. 2010, 1252, 269-277. [CrossRef]

28. Alexa, V.; Raţiu, S.; Kiss, I. Metal rolling-Asymmetrical rolling process. IOP Conf. Ser. Mater. Sci. Eng. 2016, 106. [CrossRef]

29. Salimi, M.; Sassani, F. Modified slab analysis of asymmetrical plate rolling. Int. J. Mech. Sci. 2002, 44, $1999-2023$. [CrossRef]

30. Salimi, M.; Kadkhodaei, M. Slab analysis of asymmetrical sheet rolling. J. Mater. Process. Technol. 2004, 150, 215-222. [CrossRef]

31. Qwamizadeh, M.; Kadkhodaei, M.; Salimi, M. Asymmetrical sheet rolling analysis and evaluation of developed curvature. Int. J. Adv. Manuf. Technol. 2012, 61, 227-235. [CrossRef]

32. Dyja, H.; Korczak, P.; Pilarczyk, J.W.; Grzybowski, J. Theoretical and experimental analysis of plates asymmetric rolling. J. Mater. Process. Tech. 1994, 45, 167-172. [CrossRef]

33. Richelsen, A.B. Comparison of a numerical analysis of rolling with experimental data. J. Mater. Process. Technol. 1996, 57, 70-78. [CrossRef]

34. Ji, Y.; Park, J. Development of severe plastic deformation by various asymmetric rolling processes. Mater. Sci. Eng. A 2009, 499, 14-17. [CrossRef]

35. Grydin, O.; Andreiev, A.; Briukhanov, A.; Briukhanova, Z.; Schaper, M. Evolution of Microstructure, Properties and Texture of a Two-Phase Low-Carbon Steel at Cold Asymmetric Rolling. Steel Res. Int. 2017, 88, 1-9. [CrossRef]

36. Roumina, R.; Sinclair, C.W. Deformation geometry and through-thickness strain gradients in asymmetric rolling. Metall. Mater. Trans. A Phys. Metall. Mater. Sci. 2008, 39, 2495-2503. [CrossRef]

37. Li, L.; Matsumoto, R.; Utsunomiya, H. Curling of sheet in asymmetric rolling investigated by profile measurement of partly rolled sheet. ISIJ Int. 2019, 59, 489-495. [CrossRef]

38. Lu, J.S.; Harrer, O.K.; Schwenzfeier, W.; Fischer, F.D. Analysis of the bending of the rolling material in asymmetrical sheet rolling. Int. J. Mech. Sci. 2000, 42, 49-61. [CrossRef] 
39. Lee, S.H.; Lee, D.N. Analysis of deformation textures of asymmetrically rolled steel sheets. Int. J. Mech. Sci. 2001, 43, 1997-2015. [CrossRef]

40. Kim, K.H.; Lee, D.N. Analysis of deformation textures of asymmetrically rolled aluminum sheets. Acta Mater. 2001, 49, 2583-2595. [CrossRef]

41. Ghobrial, M. A photoelastic investigation on the contact stresses developed in rolls during asymmetrical flat rolling. Int. J. Mech. Sci. 1989, 31, 751-764. [CrossRef]

42. Pesin, A.M.; Pustovoitov, D.O.; Biryukova, O.D. The effect of speed asymmetry on the strain state in aluminium bimetals during accumulative rolling. IOP Conf. Ser. Mater. Sci. Eng. 2018, 447. [CrossRef]

43. Jin, H.; Lloyd, D.J. The different effects of asymmetric rolling and surface friction on formation of shear texture in aluminium alloy AA5754. Mater. Sci. Technol. 2010, 26, 754-760. [CrossRef]

44. Lequeu, P.; Jonas, J.J. Modeling of the plastic anisotropy of textured sheet. Metall. Trans. A 1988, 19, $105-120$. [CrossRef]

45. Jonas, J.J.; Butron-Guillen, M.P.; Savoie, J. Transformation Textures in Steels. ISIJ Int. 1994, 34, 927-942. [CrossRef]

46. Engler, O.; Kim, H.C.; Huh, M.Y. Formation of $\{111\}$ fibre texture in recrystallised aluminium sheet. Mater. Sci. Technol. 2001, 17, 75-86. [CrossRef]

47. Choi, C.H.; Kim, K.H.; Lee, D.N. The Effect of Shear Texture Development on the Formability in Rolled Aluminum Alloys Sheets. Mater. Sci. Forum 1998, 273-275, 391-396. [CrossRef]

48. Kim, K.H.; Lee, D.N.; Choi, C.H.; Szpunar, J.A. The deformation textures and lankford values of asymmetrically rolled aluminum alloy sheet. In Proceedings of the 12th International Conference on Textures of Materials, Montreal, QC, Canada, 9-13 August 1999; Volume 1, pp. 755-760.

49. Sakai, T.; Hamada, S.; Saito, Y. Improvement of the r-value in 5052 aluminum alloy sheets having through-thickness shear texture by 2-pass single-roll drive unidirectional shear rolling. Scr. Mater. 2001, 44, 2569-2573. [CrossRef]

50. Jin, H.; Lloyd, D.J. The reduction of planar anisotropy by texture modification through asymmetric rolling and annealing in AA5754. Mater. Sci. Eng. A 2005, 399, 358-367. [CrossRef]

51. Lomana, M.; Rodríguez, A.; Tamayo, J.; Zubillaga, C.; García-Rosales, C.; Gil Sevillano, J. Modificación de las texturas y de los índices de embutibilidad de chapas de aleaciones de aluminio Al 1050 y Al-Mg 5754 mediante laminación asimétrica. Boletín de la Sociedad Española de Cerámica y Vidrio 2004, 43, 175-178. [CrossRef]

52. Kim, I.; Akramov, S.; Jeong, H.B. Texture and formability development of asymmetry rolled AA 3003 AL alloy sheet. Int. J. Mod. Phys. B 2008, 22, 5895-5900. [CrossRef]

53. Kang, S.B.; Min, B.K.; Kim, H.W.; Wilkinson, D.S.; Kang, J. Effect of asymmetric rolling on the texture and mechanical properties of AA6111-aluminum sheet. Metall. Mater. Trans. A 2005, 36, 3141-3149. [CrossRef]

54. Zanchetta, B.D.; Da Silva, V.K.; Sordi, V.L.; Rubert, J.B.; Kliauga, A.M. Effect of asymmetric rolling under high friction coefficient on recrystallization texture and plastic anisotropy of AA1050 alloy. Trans. Nonferr. Met. Soc. China (Engl. Ed.) 2019, 29, 2262-2272. [CrossRef]

55. Cho, J.H.; Kim, H.W.; Lim, C.Y.; Kang, S.B. Microstructure and mechanical properties of Al-Si-Mg alloys fabricated by twin roll casting and subsequent symmetric and asymmetric rolling. Met. Mater. Int. 2014, 20, 647-652. [CrossRef]

56. Nam, S.K.; Lee, J.H.; Kim, G.H.; Lee, D.N.; Kim, I. Texture Analysis for Enhancement of R-value in Asymmetrically Rolled Al Alloy Sheet. J. Mater. Eng. Perform. 2019, 28, 5186-5194. [CrossRef]

57. Simões, F.J.; de Sousa, R.J.; Grácio, J.J.; Barlat, F.; Yoon, J.W. Effect of asymmetrical rolling and annealing on the mechanical response of an AA1050-O sheet. Int. J. Mater. Form. 2009, 2, 891-894. [CrossRef]

58. Shore, D.; Kestens, L.A.; Sidor, J.; Van Houtte, P.; Van Bael, A. Process parameter influence on texture heterogeneity in asymmetric rolling of aluminium sheet alloys. Int. J. Mater. Form. 2018, 11, 297-309. [CrossRef]

59. Kraner, J.; Fajfar, P.; Palkowski, H.; Kugler, G.; Godec, M.; Paulin, I. Microstructure and texture evolution with relation to mechanical properties of compared symmetrically and asymmetrically cold rolled aluminum alloy. Metals 2020, 10, 156. [CrossRef]

60. Jin, H.; Lloyd, D.J. Evolution of texture in AA6111 aluminum alloy after asymmetric rolling with various velocity ratios between top and bottom rolls. Mater. Sci. Eng. A 2007, 465, 267-273. [CrossRef] 
61. Suzuki, Y.; Noguchi, O.; Miki, Y.; Ueno, Y.; Koyama, K.; Komatsubara, T. Evolution of Recrystallization Texture in Aluminum Alloy Sheets by Asymmetric-Warm-Rolling. In Proceedings of the 12th International Conference on Aluminium Alloys, Yokohama, Japan, 5-9 September 2010; The Japan Institute of Light Metals: Tokyo, Japan, 2010; pp. 137-142.

62. Miki, Y.; Noguchi, O.; Ueno, Y.; Suzuki, Y.; Koyama, K.; Komatsubara, T. Improvement of Deep Drawability of Al-Mg-Si Alloy Sheets for Automotive Panel by Asymmetric Warm Rolling. In Proceedings of the 12th International Conference on Aluminium Alloys, Yokohama, Japan, 5-9 September 2010; The Japan Institute of Light Metals: Tokyo, Japan, 2010; pp. 1225-1230.

63. Ren, X.; Huang, Y.; Liu, Y.; Zhao, Y.; Li, H. Evolution of microstructure, texture, and mechanical properties in a twin-roll cast AA6016 sheet after asymmetric rolling with various velocity ratios between top and bottom rolls. Mater. Sci. Eng. A 2020, 788, 139448. [CrossRef]

64. Cheon, B.H.; Kim, H.W.; Lee, J.C. Asymmetric rolling of strip-cast Al-5.5Mg-0.3Cu alloy sheet: Effects on the formability and mechanical properties. Mater. Sci. Eng. A 2011, 528, 5223-5227. [CrossRef]

65. Son, S.G.; Kim, H.K.; Cho, J.H.; Kim, H.W.; Lee, J.C. Differential speed rolling of twin-roll-cast $6 x x x$ al alloy strips and its influence on the sheet formability. Met. Mater. Int. 2016, 22, 108-117. [CrossRef]

66. Ren, X.; Zhang, X.; Huang, Y.; Liu, Y.; Zhao, L.; Zhou, W. Evolution of shear texture during the asymmetric rolling and its annealing behavior in a twin-roll casting AA6016 sheet: An ex-situ electron backscatter diffraction study. J. Mater. Res. Technol. 2020, 9, 6420-6433. [CrossRef]

67. Wroński, S.; Wierzbanowski, K.; Bacroix, B.; Chauveau, T.; Wróbel, M. Effect of asymmetric rolling on mechanical characteristics, texture and misorientations in ferritic steel. J. Cent. South Univ. 2013, 20, 1443-1455. [CrossRef]

68. Orlov, D.; Lapovok, R.; Toth, L.S.; Timokhina, I.B.; Hodgson, P.D.; Haldar, A.; Bhattacharjee, D. Asymmetric rolling of interstitial-free steel using differential roll diameters. Part II: Microstructure and annealing effects. Metall. Mater. Trans. A Phys. Metall. Mater. Sci. 2014, 45, 447-454. [CrossRef]

69. Tóth, L.S.; Beausir, B.; Orlov, D.; Lapovok, R.; Haldar, A. Analysis of texture and R value variations in asymmetric rolling of if steel. J. Mater. Process. Technol. 2012, 212, 509-515. [CrossRef]

70. Lapovok, R.; Orlov, D.; Timokhina, I.B.; Pougis, A.; Toth, L.S.; Hodgson, P.D.; Haldar, A.; Bhattacharjee, D. Asymmetric rolling of interstitial-free steel using one idle roll. Metall. Mater. Trans. A Phys. Metall. Mater. Sci. 2012, 43, 1328-1340. [CrossRef]

71. Wauthier, A.; Regle, H.; Formigoni, J.; Herman, G. The effects of asymmetrical cold rolling on kinetics, grain size and texture in IF steels. Mater. Charact. 2009, 60, 90-95. [CrossRef]

72. Tamimi, S.; Gracio, J.J.; Lopes, A.B.; Ahzi, S.; Barlat, F. Asymmetric rolling of interstitial free steel sheets: Microstructural evolution and mechanical properties. J. Manuf. Process. 2018, 31, 583-592. [CrossRef]

73. Dhinwal, S.S.; Toth, L.S.; Lapovok, R.; Hodgson, P.D. Tailoring one-pass asymmetric rolling of extra low carbon steel for shear texture and recrystallization. Materials 2019, 12, 1935. [CrossRef]

74. Dong, F.; Xue, F.; Du, L.; Liu, X. Promoting $\mathrm{Ti}_{4} \mathrm{C}_{2} \mathrm{~S}_{2}$ strain induced precipitation during asymmetrical hot rolling to improve r value and advantaged texture in Ti stabilized IF steel. J. Alloy. Compd. 2015, 620, $240-248$. [CrossRef]

75. Barella, S.; Mapelli, C. Mechanical properties and textures of duplex stainless steel rolled worked by asymmetric rolling. Int. J. Mater. Form. 2011, 4, 379-388. [CrossRef]

76. Amininejad, A.; Jamaati, R.; Hosseinipour, S.J. Achieving superior strength and high ductility in AISI 304 austenitic stainless steel via asymmetric cold rolling. Mater. Sci. Eng. A 2019, 767, 138433. [CrossRef]

77. Chen, S.D.; Liu, X.H.; Liu, L.Z. Symmetric and asymmetric rolling pure copper foil: Crystal plasticity finite element simulation and experiments. Acta Metall. Sin. Engl. Lett. 2015, 28, 1024-1033. [CrossRef]

78. Berrenberg, F.; Wang, J.; Timokhina, I.; Haase, C.; Lapovok, R.; Molodov, D.A. Influence of rolling asymmetry on the microstructure, texture and mechanical behavior of high-manganese twinning-induced plasticity steel. Mater. Sci. Eng. A 2018, 709, 172-180. [CrossRef]

79. Brasche, F.; Wang, J.; Timokhina, I.; Haase, C.; Lapovok, R.; Molodov, D.A. Mechanical twinning and texture evolution during asymmetric warm rolling of a high manganese steel. Mater. Sci. Eng. A 2019, 764, 138183. [CrossRef]

80. Sha, Y.; Zhang, F.; Zhou, S.; Pei, W.; Zuo, L. Improvement of recrystallization texture and magnetic property in non-oriented silicon steel by asymmetric rolling. J. Magn. Magn. Mater. 2008, 320, 393-396. [CrossRef] 
81. Chen, S.; Butler, J.; Melzer, S. Effect of asymmetric hot rolling on texture, microstructure and magnetic properties in a non-grain oriented electrical steel. J. Magn. Magn. Mater. 2014, 368, 342-352. [CrossRef]

82. Cui, Q.; Ohori, K. Grain refinement of high purity aluminium by asymmetric rolling. Mater. Sci. Technol. 2000, 16, 1095-1101. [CrossRef]

83. Jin, H.; Lloyd, D.J. The tensile response of a fine-grained AA5754 alloy produced by asymmetric rolling and annealing. Metall. Mater. Trans. A 2004, 35, 997-1006. [CrossRef]

84. Ding, Y.; Jiang, J.; Shan, A. Plastic instability and strain rate sensitivity of ultrafine-grained iron. J. Alloy. Compd. 2009, 487, 517-521. [CrossRef]

85. Sidor, J.J.; Petrov, R.H.; Kestens, L.A. Microstructural and texture changes in severely deformed aluminum alloys. Mater. Charact. 2011, 62, 228-236. [CrossRef]

86. Wroński, S.; Bacroix, B. Texture and microstructure variation in asymmetrically rolled steel. Mater. Charact. 2016, 118, 235-243. [CrossRef]

87. Ma, C.; Hou, L.; Zhang, J.; Zhuang, L. Influence of thickness reduction per pass on strain, microstructures and mechanical properties of $7050 \mathrm{Al}$ alloy sheet processed by asymmetric rolling. Mater. Sci. Eng. A 2016, 650, 454-468. [CrossRef]

88. Bintu, A.; Vincze, G.; Picu, R.; Lopes, A. Effect of symmetric and asymmetric rolling on the mechanical properties of AA5182. Mater. Des. 2016, 100, 151-156. [CrossRef]

89. Ma, B.; Li, C.; Wang, J.; Cai, B.; Sui, F. Influence of asymmetric hot rolling on through-thickness microstructure gradient of Fe-20Mn-4Al-0.3C non-magnetic steel. Mater. Sci. Eng. A 2016, 671, 190-197. [CrossRef]

90. Hamad, K.; Ko, Y.G. Annealing Characteristics of Ultrafine Grained Low-Carbon Steel Processed by Differential Speed Rolling Method. Metall. Mater. Trans. A 2016, 47, 2319-2334. [CrossRef]

91. Cai, M.H.; Singh Dhinwal, S.; Han, Q.H.; Chao, Q.; Hodgson, P.D. Gradient ultrafine ferrite and martensite structure and its tensile properties by asymmetric rolling in low carbon microalloyed steel. Mater. Sci. Eng. A 2013, 583, 205-209. [CrossRef]

92. Kudrathon, B. Asymmetric Rolling of Aluminium 1050. Master's Thesis, Universidade de Aveiro, Aveiro, Portugal, 2010.

93. Orlov, D.; Pougis, A.; Lapovok, R.; Toth, L.S.; Timokhina, I.B.; Hodgson, P.D.; Haldar, A.; Bhattacharjee, D. Asymmetric Rolling of Interstitial-Free Steel Using Differential Roll Diameters. Part I: Mechanical Properties and Deformation Textures. Metall. Mater. Trans. A 2013, 44, 4346-4359. [CrossRef]

94. Knight, C.W.; Hardy, S.J.; Lees, A.W.; Brown, K.J. Investigations into the influence of asymmetric factors and rolling parameters on strip curvature during hot rolling. J. Mater. Process. Technol. 2003, 134, 180-189. [CrossRef]

95. Markowski, J.; Dyja, H.; Knapiński, M.; Kawałek, A. Theoretical analysis of the asymmetric rolling of sheets on leader and finishing stands. J. Mater. Process. Technol. 2003, 138, 183-188. [CrossRef]

96. Kawałek, A. Forming of band curvature in asymmetrical rolling process. J. Mater. Process. Technol. 2004, 155-156, 2033-2038. [CrossRef]

97. Shatalov, R.L.; Maksimov, E.A.; Babkin, A.G. Adjustment of rolling mills to produce flatter steel strip. Steel Transl. 2011, 41, 845-848. [CrossRef]

98. Grácio, J.J.; Vincze, G.; Yoon, J.W.; Cardoso, R.P.R.; Rauch, E.F.; Barlat, F.G. Modeling the Effect of Asymmetric Rolling on Mechanical Properties of Al-Mg Alloys. Steel Res. Int. 2015, 86, 922-931. [CrossRef]

99. Gracio, J.J.; Kim, H.J.; Vincze, G.; Panigrahi, B.B.; Barlat, F.; Rauch, E.F.; Yoon, J.W.; Barlat, F.; Moon, Y.H.; Lee, M.G. Effect of Asymmetric Rolling on Plastic Anisotropy of Low Carbon Steels during Simple Shear Tests. In Proceedings of the 10th International Conference on Numerical Methods in Industrial Forming Processes (NUMIFORM 2010), Pohang, Korea, 13-17 June 2010; pp. 181-184. [CrossRef]

100. Ren, J.; Chen, Z.; Peng, J.; Ma, W.; Ringer, S.P. An initial report on achieving high comprehensive performance in an Al-Mg-Si alloy via novel thermomechanical processing. J. Alloy. Compd. 2018, 764, 679-683. [CrossRef]

(C) 2020 by the authors. Licensee MDPI, Basel, Switzerland. This article is an open access article distributed under the terms and conditions of the Creative Commons Attribution (CC BY) license (http:/ / creativecommons.org/licenses/by/4.0/). 